\title{
Newly Designed Luminescent Di- and Tetra-nuclear Double Rollover Cycloplatinated(II) Complexes
}

\author{
Reza Babadi Aghakhanpour, S. Masoud Nabavizadeh,* and Mehdi Rashidi* \\ Department of Chemistry, College of Sciences, Shiraz University, Shiraz, 71454, Iran
}

Corresponding Authors:

S. Masoud Nabavizadeh

E-mail:Nabavi@chem.susc.ac.ir

Mehdi Rashidi

E-mail:Rashidi@chem.susc.ac.ir

(C) 2016. This manuscript version is made available under the Elsevier user license http://www.elsevier.com/open-access/userlicense/1.0/ 


\begin{abstract}
The known binuclear complex $\left[\mathrm{Pt}_{2}(\mu-\mathrm{bpy}-2 \mathrm{H})(\mathrm{Me})_{2}(\mathrm{DMSO})_{2}\right], \mathbf{1}$, in which bpy = 2,2'-bipyridine and DMSO = dimethyl sulfoxide, was reacted with 2 equiv bis(diphenylphosphino)methane, dppm, to give the new double rollover cycloplatinated(II) complex $\left[\mathrm{Pt}_{2}(\mu-b p y-2 \mathrm{H})(\mathrm{Me})_{2}\left(\kappa^{1}-\right.\right.$ dppm) $)_{2}$, 2, in which each metallic center bears a monodentate dppm ligand. The reaction of $\mathbf{2}$ with 2 equiv of the known monomeric cycloplatinated (II) complex [Pt(Me)(bhq-H)(SMe 2$)]$, in which bhq $=7,8$-benzo $[h]$ quinoline, gave the new unsymmetrical tetranuclear complex $[\{($ bhq$\left.\mathrm{H})(\mathrm{Me}) \operatorname{Pt}(\mu-\mathrm{dppm}) \operatorname{Pt}(\mathrm{Me})\}_{2}(\mu-\mathrm{bpy}-2 \mathrm{H})\right]$, 3. The complexes were fully characterized using multinuclear $\left({ }^{1} \mathrm{H}\right.$ and $\left.{ }^{31} \mathrm{P}\left\{{ }^{1} \mathrm{H}\right\}\right)$ NMR spectroscopy and elemental analysis. Photophysical properties of the synthesized complexes were investigated and the results were confirmed by DFT calculations. The complexes 1-3 are brightly luminescent in solution and solid state. The complex 1 exhibits structured emission band, complying with the cyclometalated ligand being the centered emissive state. The complexes $\mathbf{2}$ and $\mathbf{3}$, however, exhibit unstructured emission bands, confirming a large amount of MLCT in their emissive states.
\end{abstract}

Keywords: Roll-over cycloplatinated, Biphosphine, Photoluminescence, DFT calculations

\title{
1. Introduction
}

Intramolecular $\mathrm{C}-\mathrm{H}$ bond activation has become an important topic of interest for the last decades [1-5]. Syntheses of late transition metal cyclometalated derivatives with heterocyclic nitrogen ligands are of great interest due to the wide applications of the resulting complexes in 
synthesis of organic compounds [6,7], homogeneous catalysis [8-10], medicinal chemistry [11], novel materials [12], photochemistry [13-17], and chemical and biochemical sensors [18-22].

Classical bidentate $\mathrm{C}^{\wedge} \mathrm{N}$ cyclometalated complexes have mostly been addressed to late transition metal derivatives for their applications in luminescent devices [23], chemosensors [24], switches [25], and metallomesogens $[26,27]$. The planar nature of five-membered $\mathrm{C}^{\wedge} \mathrm{N}$ cyclometalated moieties implies a delocalized $\pi$ system which can improve the photophysical and photochemical properties of the corresponding complexes.

Normally, 2,2`-bipyridine derivatives act as $\mathrm{N}^{\wedge} \mathrm{N}$ bidentate ligands but in recent years they have found a new mode of coordination as $\mathrm{C}^{\wedge} \mathrm{N}$ bidentate ligands. This new mode of cyclometalation is named "Roll-over cyclometalation" as one of the two pyridine rings is coordinated via its $\mathrm{N}$ atom while the other one rolls along the bond between two pyridine rings.[28] This rotation, performing under special conditions, is taken place in such a way to locate the $3-\mathrm{C}-\mathrm{H}$ bond in front of metal center to establish the $\mathrm{C}-\mathrm{H}$ bond activation and finally the $\mathrm{N}^{\wedge} \mathrm{N}$ chelate is converted to $\mathrm{C}^{\wedge} \mathrm{N}$ chelate (Scheme 1). There are now only a few examples of roll-over cyclometalation complexes of Ir(III), [29] Rh(III) [30] , Pd(II), [31] Pt(II), [32] and $\mathrm{Au}(\mathrm{III})$ [33].

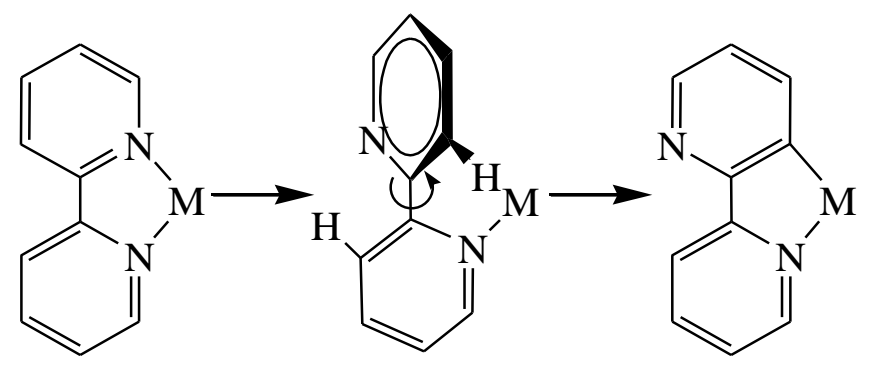

Scheme 1. Bipyridine is rolling along the bond between two pyridine rings.

Among the late transition metals, roll-over cycloplatinated(II) complexes have been most investigated, as they have shown to be active in the dehydrosulfurization and oxidative $\mathrm{C}-\mathrm{C}$ bond 
coupling of thioethers in the gas phase [34]. Zucca and his research group are pioneers in the field of roll-over cyclometalation and in recent years they have had many valuable publications in this field, including cases where "double roll-over" systems are involved.[31, 33, 35-41] In the present study, attempts have been made to synthesize an interesting tetranuclear Pt(II) complex containing two classical cycloplatinated moieties bridging through a double roll-over cycloplatinated species. The luminescence properties of these complexes, supported by theoretical calculations, are also investigated.

\section{Experimental Section}

${ }^{1} \mathrm{H}$ NMR and ${ }^{31} \mathrm{P}\left\{{ }^{1} \mathrm{H}\right\} \mathrm{NMR}$ spectra in $\mathrm{CDCl}_{3}$ were respectively recorded using Bruker Avance DPX 250 spectrometer (with TMS as reference) and Bruker Ultrashield 400 spectrometer (with $85 \% \mathrm{H}_{3} \mathrm{PO}_{4}$ as reference). The microanalyses were performed using a ThermoFinigan Flash EA1112 CHNSO rapid elemental analyzer. Photoluminescence solution and solid states spectra were recorded on a PerkinElmer LS45 Fluorescence spectrometer at room temperature. bis(diphenylphosphino)methane (dppm) were purchased from commercial sources and the complexes [ $\left.\mathrm{Pt}_{2}(\mu-b p y-2 \mathrm{H})(\mathrm{Me})_{2}(\mathrm{DMSO})_{2}\right]$, 1, [42] and $\left[\mathrm{Pt}(\mathrm{Me})(\mathrm{bhq}-\mathrm{H})\left(\mathrm{SMe}_{2}\right)\right]$ [43] were prepared as reported. The NMR labeling is shown in Scheme 4.

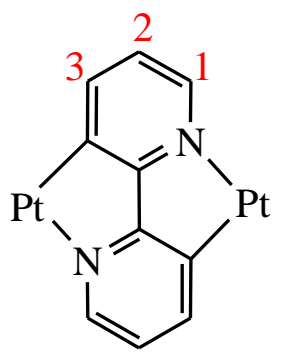<smiles>CCN1[C]=Cc2cccc3cccc1c23</smiles><smiles>PCPCP</smiles>

Scheme 3. NMR labeling. 


\section{1. $\left[\operatorname{Pt}_{2}(\mu-b p y-2 H)(M e)_{2}\left(\kappa^{1}-\mathrm{dppm}\right)_{2}\right], 2$.}

Dppm (26.3 mg, $0.068 \mathrm{mmol})$ was added to a solution of $\left[\mathrm{Pt}_{2}(\mu-\mathrm{bpy}-2 \mathrm{H})(\mathrm{Me})_{2}(\mathrm{DMSO})_{2}\right], \mathbf{1},(25$ $\mathrm{mg}, 0.034 \mathrm{mmol})$ in dichloromethane $(5 \mathrm{ml})$. This was stirred at r.t. for $2 \mathrm{~h}$ and then the solvent was removed by rotary evaporator. Finally, the yellow residue was washed with diethylether and cold acetone to remove the impurities. Yield: $64 \%$, m.p. $=221{ }^{\circ} \mathrm{C} . \mathrm{C}_{62} \mathrm{H}_{56} \mathrm{~N}_{2} \mathrm{P}_{4} \mathrm{Pt}_{2}$ : calcd $\mathrm{C}$, 55.44; H, 4.20; N, 2.09. Found: C, 55.15; H, 4.48; N, 2.30\%. NMR data in $\mathrm{CDCl}_{3}: \delta\left({ }^{1} \mathrm{H}\right)=0.73$ $\left[\mathrm{d}, 6 \mathrm{H},{ }^{3} J_{\mathrm{HP}(\mathrm{a})}=7.2 \mathrm{~Hz},{ }^{2} J_{\mathrm{PtH}}=81.3 \mathrm{~Hz}, \mathrm{Pt}-\mathrm{Me}\right] ; 3.35\left[\mathrm{~m}, 4 \mathrm{H},{ }^{2} J_{\mathrm{HP}(\mathrm{a})}=8.1 \mathrm{~Hz}, J_{\mathrm{PtH}}=24.1 \mathrm{~Hz}, \mathrm{CH}_{2}\right.$ of dppm]; $6.51\left[\mathrm{~d}, 2 \mathrm{H},{ }^{3} J_{\mathrm{H}} \mathrm{H}^{2}=7.9 \mathrm{~Hz},{ }^{3} J_{\mathrm{PtH}}{ }^{3}=33.4 \mathrm{~Hz}, \mathrm{H}^{3}\right.$ of bpy-2H]; $8.01\left[\mathrm{~d}, 2 \mathrm{H},{ }^{3} J_{\mathrm{H}} \mathrm{H}^{2}=7.5\right.$ $\mathrm{Hz},{ }^{3} J_{\mathrm{PtH}}{ }^{1}=43.6 \mathrm{~Hz}, \mathrm{H}^{1}$ of bpy-2H]; $\delta\left({ }^{31} \mathrm{P}\left\{{ }^{1} \mathrm{H}\right\}\right)=-26.0\left[\mathrm{~d}, 2 \mathrm{P},{ }^{2} J_{\mathrm{P}(\mathrm{b}) \mathrm{P}(\mathrm{a})}=76 \mathrm{~Hz},{ }^{3} J_{\mathrm{PtP}(\mathrm{b})}=54 \mathrm{~Hz}\right.$, $\mathrm{P}(\mathrm{b})] ; 18.1\left[\mathrm{~d}, 2 \mathrm{P},{ }^{2} J_{\mathrm{P}(\mathrm{a}) \mathrm{P}(\mathrm{b})}=76 \mathrm{~Hz},{ }^{1} J_{\mathrm{PtP}(\mathrm{a})}=2329 \mathrm{~Hz}, \mathrm{P}(\mathrm{a})\right]$.

\section{2. $\left[\{(\text { bhq-H })(M e) \operatorname{Pt}(\mu-d p p m) \operatorname{Pt}(M e)\}_{2}(\mu-b p y-2 H)\right], 3$.}

[Pt(Me)(bhq-H)(SMe $)](16.2 \mathrm{mg}, 0.036 \mathrm{mmol})$ was added to a solution of $\left[\mathrm{Pt}_{2}(\mu-\mathrm{bpy}-\right.$ $\left.2 \mathrm{H})(\mathrm{Me})_{2}\left(\kappa^{1}-\mathrm{dppm}\right)_{2}\right], 2(25 \mathrm{mg}, 0.018 \mathrm{mmol})$ in dichloromethane $(5 \mathrm{ml})$. This was stirred at r.t. for $2 \mathrm{~h}$ and then the solvent was removed by rotary evaporator. Finally, the orange residue was washed with diethylether and cold acetone to remove the impurities. Yield: $71 \%$, m.p. $=249{ }^{\circ} \mathrm{C}$ (decomp.). $\mathrm{C}_{90} \mathrm{H}_{78} \mathrm{~N}_{4} \mathrm{P}_{4} \mathrm{Pt}_{4}$ : calcd C, 50.99; H, 3.71; N, 2.64. Found: C, 50.48; H, 4.08; N, $2.49 \%$. NMR data in $\mathrm{CDCl}_{3}: \delta\left({ }^{1} \mathrm{H}\right)=0.67\left[\mathrm{~d}, 6 \mathrm{H},{ }^{3} J_{\mathrm{HP}}=6.4 \mathrm{~Hz},{ }^{2} J_{\mathrm{PtH}}=78.1 \mathrm{~Hz}, \mathrm{Pt}-\mathrm{Me}\right] ; 1.07[\mathrm{~d}, 6 \mathrm{H}$, $\left.{ }^{3} J_{\mathrm{HP}}=7.9 \mathrm{~Hz},{ }^{2} J_{\mathrm{PtH}}=84.4 \mathrm{~Hz}, \mathrm{Pt}-\mathrm{Me}\right] ; 4.04$ [m, $4 \mathrm{H}, \mathrm{CH}_{2}$ of dppm]; aromatic region : 6.00-8.27 ppm; $\delta\left({ }^{31} \mathrm{P}\left\{{ }^{1} \mathrm{H}\right\}\right)=19.3\left[\mathrm{~d}, 2 \mathrm{P},{ }^{2} J_{\mathrm{PP}}=14 \mathrm{~Hz},{ }^{1} J_{\mathrm{PtP}}=2323 \mathrm{~Hz},{ }^{3} J_{\mathrm{PtP}}=46 \mathrm{~Hz}, \mathrm{P}\right.$ atom trans to $\mathrm{C}$ ligating atom of bhq-H]; $21.2\left[\mathrm{~d}, 2 \mathrm{P},{ }^{2} J_{\mathrm{PP}}=14 \mathrm{~Hz},{ }^{1} J_{\mathrm{PtP}}=2145 \mathrm{~Hz},{ }^{3} J_{\mathrm{PtP}}=41 \mathrm{~Hz}, \mathrm{P}\right.$ atom trans to $\mathrm{C}$ ligating atom of $\mu-b p y-2 \mathrm{H}]$. 


\subsection{Computational details}

Density functional calculations were performed with the program suite Gaussian 03 [44] using the B3LYPlevel of theory [45-47]. The LANL2DZ basis set [48-50] was chosen to describe Pt. The 6-31G(d) basis set was used for other atoms. The geometries of complexes were fully optimized by employing the density functional theory without imposing any symmetry constraints.

\section{Results and discussion}

\subsection{Synthesis and characterization of the complexes}

Synthetic routs to the new complexes are shown in Scheme 2. The starting complex $\left[\mathrm{Pt}_{2}(\mu-b p y-\right.$ $\left.2 \mathrm{H})(\mathrm{Me})_{2}(\mathrm{DMSO})_{2}\right], \mathbf{1}$, in which bpy = 2,2'-bipyridine and DMSO = dimethyl sulfoxide, was prepared as reported previously, [42] by reaction of the well-known complex $\left[\mathrm{Pt}(\mathrm{Me})_{2}(\mathrm{dmso})_{2}\right]$ with 0.5 equiv 2,2'-bipyridine (bpy) in dry toluene under reflux condition. Reaction of 1 with 2 equiv bis(diphenylphosphino)methane, dppm, gave the new double rollover cycloplatinated(II) complex $\left[\mathrm{Pt}_{2}(\mu-\mathrm{bpy}-2 \mathrm{H})(\mathrm{Me})_{2}\left(\kappa^{1}-\mathrm{dppm}\right)_{2}\right], 2$. Reaction of the binuclear complex 2, containing one monodentate dppm ligand on each Pt center, with 2 equiv of the known monomeric complex $\left[\mathrm{Pt}(\mathrm{Me})\left(\mathrm{bhq}_{-\mathrm{H}}\right)\left(\mathrm{SMe}_{2}\right)\right],[43]$, in which bhq = 7,8-benzo[ $\left.h\right]$ quinoline, gave the new interesting unsymmetrical tetranuclear assembled complex $\left[\left\{(\text { bhq-H) }(\mathrm{Me}) \operatorname{Pt}(\mu-\mathrm{dppm}) \operatorname{Pt}(\mathrm{Me})\}_{2}(\mu-\mathrm{bpy}-2 \mathrm{H})\right]\right.$, 3. All the complexes were isolated as pure and stable solids that are also quite stable in solution. Although our many attempts to grow suitable crystals for X-ray analysis were not successful, structures of the complexes were fully identified using their ${ }^{1} \mathrm{H}$ and ${ }^{31} \mathrm{P}\left\{{ }^{1} \mathrm{H}\right\} \mathrm{NMR}$ spectra. In ${ }^{1} \mathrm{HNMR}$ spectrum of the binuclear complex $\left[\mathrm{Pt}_{2}(\mu-\mathrm{bpy}-2 \mathrm{H})(\mathrm{Me})_{2}\left(\kappa^{1}-\mathrm{dppm}\right)_{2}\right], 2$ (Figure 1a), a 
signal for the two equivalent Me ligands is observed at $\delta=0.73 \mathrm{ppm}$ (as a doublet due to coupling to one $\mathrm{P}$ atom with ${ }^{3} J_{\mathrm{HP}}=7.2 \mathrm{~Hz}$ ) which is coupled to the platinum center giving satellites with ${ }^{2} J_{\mathrm{PtH}}=81.3 \mathrm{~Hz}$. A broad doublet signal (with ${ }^{2} J_{\mathrm{HP}(\mathrm{a})}=8.1 \mathrm{~Hz}$ ) observing at $\delta=3.35$ ppm (see Figure 1), which is also coupled to the Pt center to give satellites with ${ }^{3} J_{\mathrm{PtH}}=24.1 \mathrm{~Hz}$, is attributed to protons of $\mathrm{CH}_{2}$ groups of the dangling dppm ligands; this kind of signal, a multiplet signal appearing as a broad doublet, is usually expected for Pt- $\left(\kappa^{1}-\mathrm{dppm}\right)$ dangling dppm ligand. Two multiplet signals observing in the aromatic region at $\delta=6.51 \mathrm{ppm}$ (with ${ }^{3} J_{\mathrm{PtH}}=33.4 \mathrm{~Hz}$ ) and $\delta=8.01 \mathrm{ppm}$ (with ${ }^{3} \mathrm{~J}_{\mathrm{PtH}}=43.6 \mathrm{~Hz}$ ) are assigned to $\mathrm{CH}$ protons adjacent to the ligating $\mathrm{C}$ atoms and $\mathrm{CH}$ protons adjacent to the ligating $\mathrm{N}$ atoms, respectively, of the $\mu$-bpy- $2 \mathrm{H}$ moiety, i.e. $\mathrm{H}^{3}$ and $\mathrm{H}^{1}$ (see NMR labeling in Scheme 3 of Experimental section). 


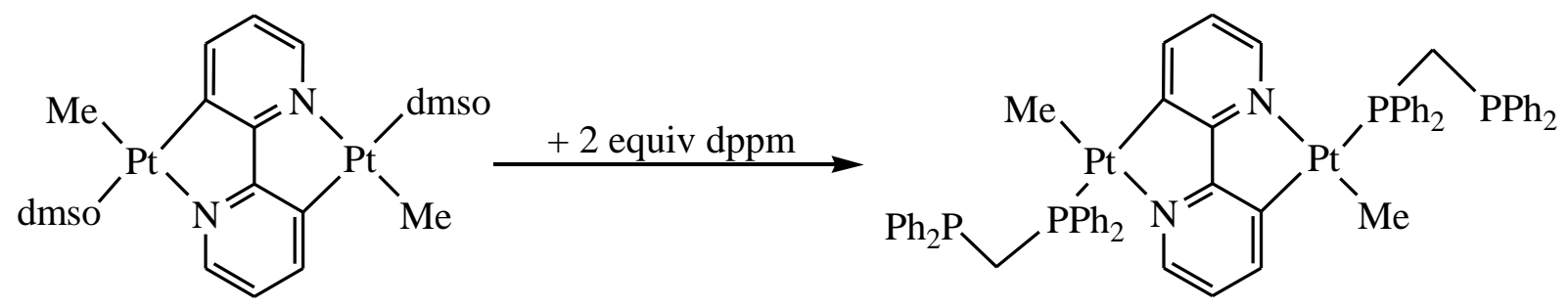

(1)

(2)

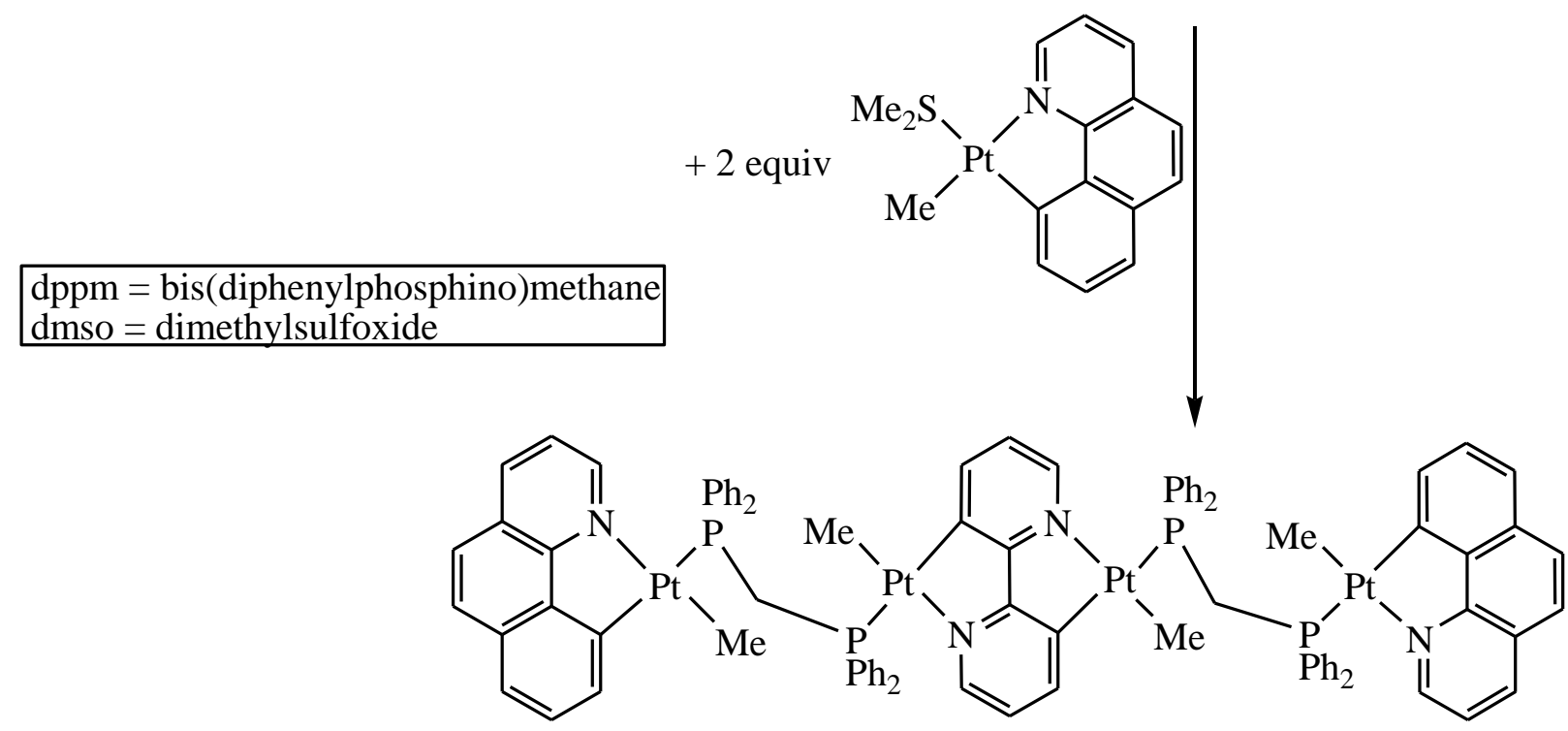

(3)

Scheme 2. Synthesis of the complexes 2 and $\mathbf{3}$. 


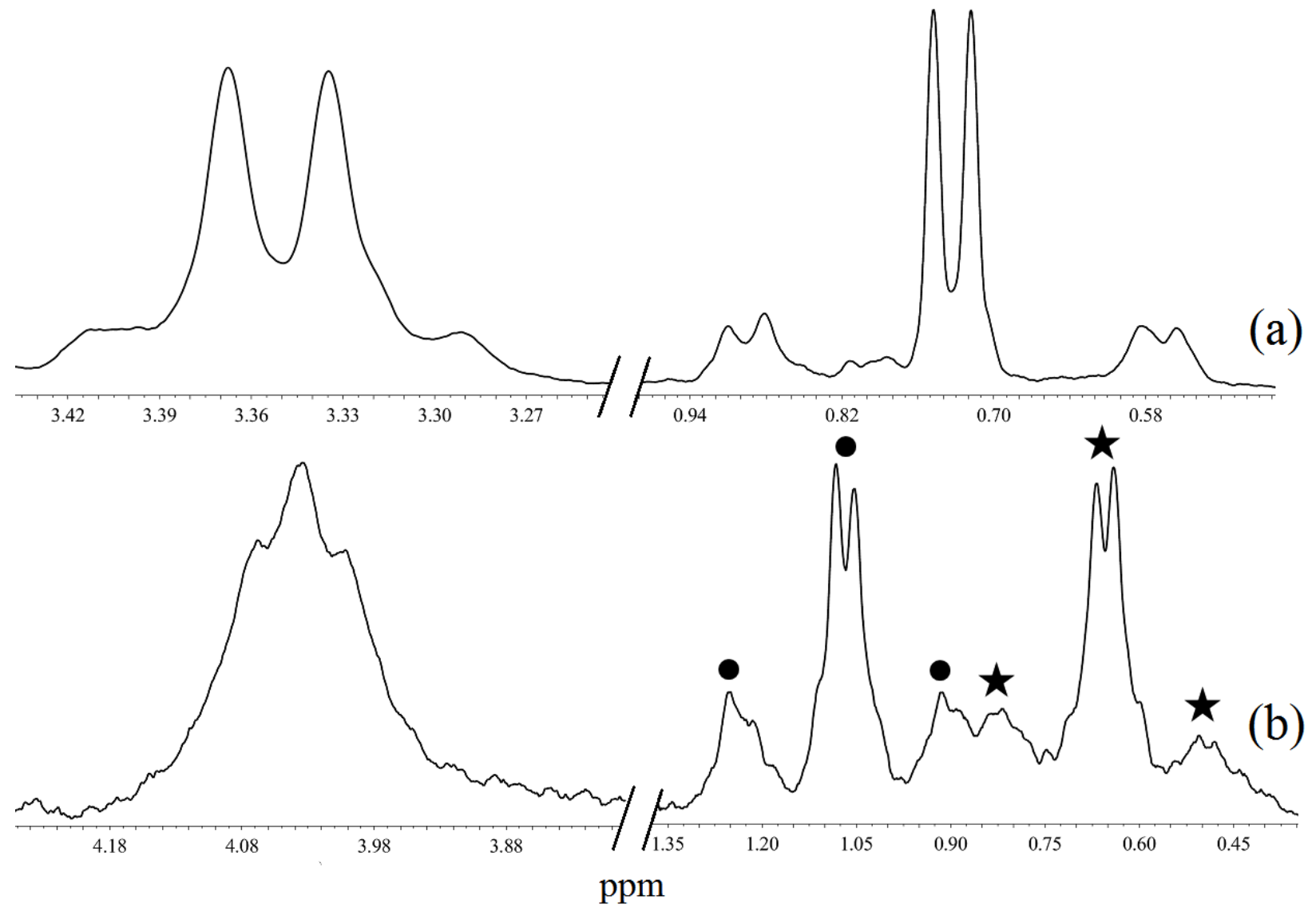

Figure 1. ${ }^{1} \mathrm{H}$ NMR spectra (in region of $\mathrm{Pt}-\mathrm{Me}$, right, and $\mathrm{CH}_{2}$ of the dppm ligands, left) in $\mathrm{CDCl}_{3}$ of: (a) $\left[\mathrm{Pt}_{2}(\mu-\text { bpy-2H)(Me })_{2}(\kappa-\mathrm{dppm})_{2}\right], \mathbf{2}$; (b) $\left[\{(\mathrm{bhq}-\mathrm{H})(\mathrm{Me}) \mathrm{Pt}(\mu-\mathrm{dppm}) \operatorname{Pt}(\mathrm{Me})\}_{2}(\mu-\right.$ bpy2H)], 3.

In the ${ }^{31} \mathrm{P}\left\{{ }^{1} \mathrm{H}\right\}$ NMR spectrum of the complex $\left[\mathrm{Pt}_{2}(\mu-\mathrm{bpy}-2 \mathrm{H})(\mathrm{Me})_{2}\left(\kappa^{1}-\mathrm{dppm}\right)_{2}\right], 2$, (Figure 2a) two nonequivalent phosphorus atoms were indicated by the observation of two doublet resonances with ${ }^{2} J_{\mathrm{PP}}=76 \mathrm{~Hz}$ at $\delta=-26.0 \mathrm{ppm}$ (for the dangled uncoordinated $\mathrm{P}$ atom of dppm), which is coupled to the Pt center with ${ }^{3} J_{\mathrm{PtP}}=54 \mathrm{~Hz}$, and $18.1 \mathrm{ppm}$ (for the coordinated $\mathrm{P}$ atom of dppm), which is coupled to the directly connected Pt center with a much bigger coupling value of ${ }^{1} J_{\mathrm{PtP}}=2329 \mathrm{~Hz}$. 


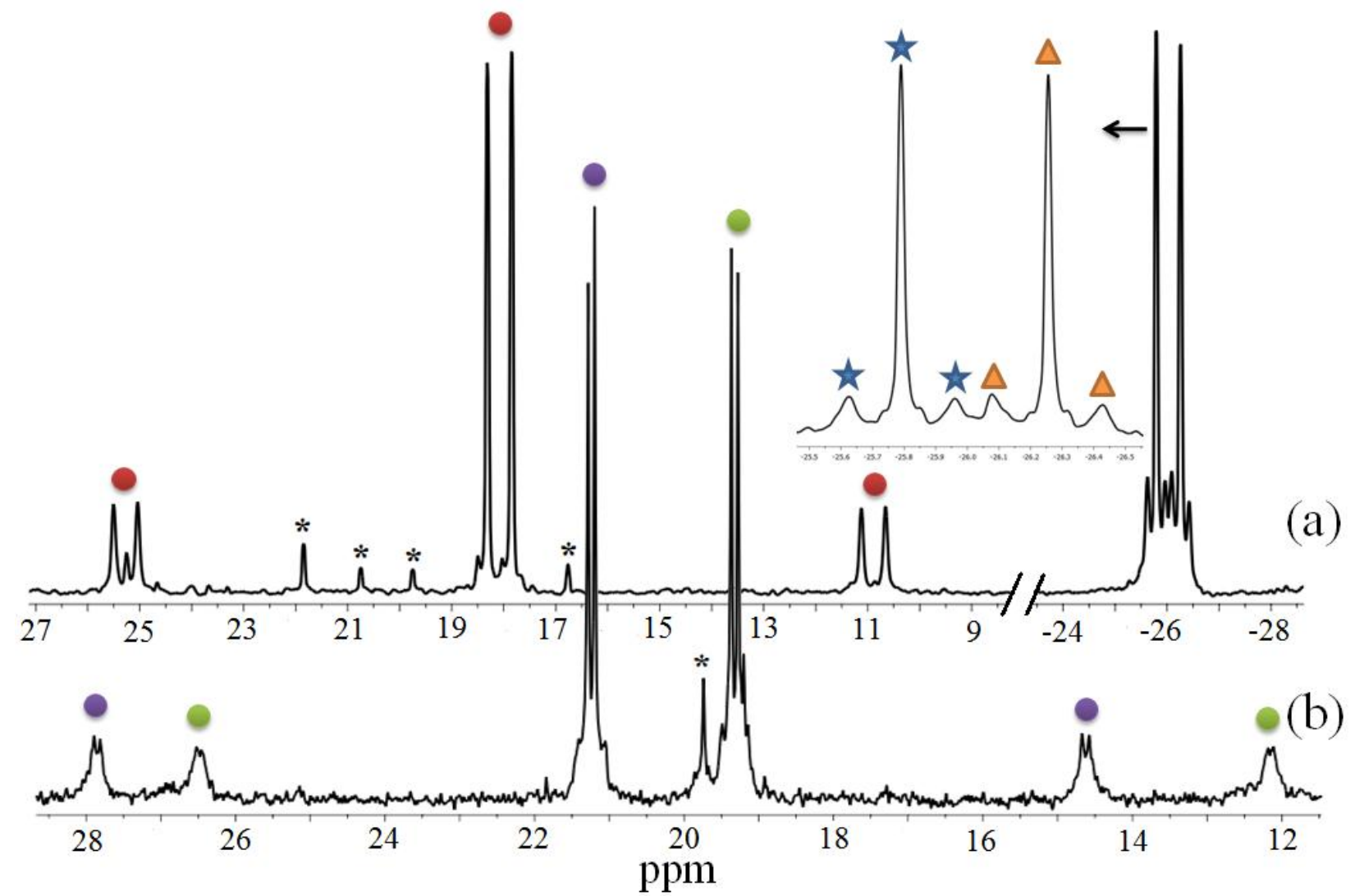

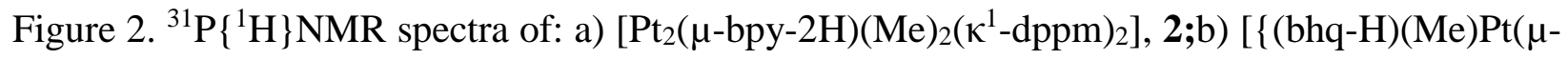
$\operatorname{dppm}) \operatorname{Pt}(\mathrm{Me})\}_{2}(\mu-$ bpy-2H)], 3 (* = trace impurity).

In ${ }^{1} \mathrm{HNMR}$ spectrum of the complex $\left[\left\{(\text { bhq-H)(Me)Pt( } \mu \text {-dppm) } \mathrm{Pt}(\mathrm{Me})\}_{2}(\mu\right.\right.$-bpy-2H)], 3 (Figure 1b), two doublet signals (each coupling to a different phosphorous atom of the corresponding bridging dppm ligand) were observed for the two different Pt-Me groups at $\delta=0.67 \mathrm{ppm}$ (with ${ }^{3} J_{\mathrm{HP}}=6.4 \mathrm{~Hz}$ and $\left.{ }^{2} J_{\mathrm{PtH}}=78.1 \mathrm{~Hz}\right)$ and $1.07 \mathrm{ppm}\left(\right.$ with ${ }^{3} J_{\mathrm{HP}}=7.9 \mathrm{~Hz}$ and $\left.{ }^{2} J_{\mathrm{PtH}}=84.4 \mathrm{~Hz}\right)$. The broad signal observing at $\delta=4.04 \mathrm{ppm}$ is attributed to protons of the $\mathrm{CH}_{2}$ groups of nonsymmetric bridging dppm ligands, as observed elsewhere.[43]

In the ${ }^{31} \mathrm{P}\left\{{ }^{1} \mathrm{H}\right\}$ NMR spectrum of complex 3 (Figure $2 b$ ), two nonequivalent phosphorus atoms of the bridging dppm ligands were indicated by the observation of two doublet resonances with 
${ }^{2} J_{\mathrm{PP}}=14 \mathrm{~Hz}$, at $\delta=19.3 \mathrm{ppm}\left(\right.$ with ${ }^{1} J_{\mathrm{PtP}}=2323 \mathrm{~Hz}$ and ${ }^{3} J_{\mathrm{PtP}}=46 \mathrm{~Hz}, \mathrm{P}$ atom trans to $\mathrm{C}$ ligating atom of bhq-H) and at $\delta=21.2 \mathrm{ppm}\left(\right.$ with ${ }^{1} J_{\mathrm{PtP}}=2145 \mathrm{~Hz}$ and ${ }^{3} J_{\mathrm{PtP}}=41 \mathrm{~Hz}, \mathrm{P}$ atom trans to C ligating atom of $\mu$-bpy-2H); these assignments are consistent with trans influence of C ligating atom of $\mu-b p y-2 \mathrm{H}$ being significantly greater than that of $\mathrm{C}$ ligating atom of bhq- $\mathrm{H}$, as confirmed by DFT studies (see below). Besides, by virtue of observing a "short range-long range" coupling pattern for each of the two different types of phosphorous atoms of bridging dppm ligands (by coupling to the connected and the distant platinum centers), and also the observation of only two types of Pt-Me resonances (in 1:1 ration) in ${ }^{1} \mathrm{H}$ NMR spectrum of the complex $\mathbf{3}$, it is quite reasonable to consider the structure of $\mathbf{3}$ as being a tetranuclear complex as depicted in Scheme 3.

\subsection{Photophysical Properties}

UV-visible absorption spectra of the complexes 1-3 in dichloromethane solution at room temperature are shown in Figure 3. The resulting photophysical data are collected in Table1.

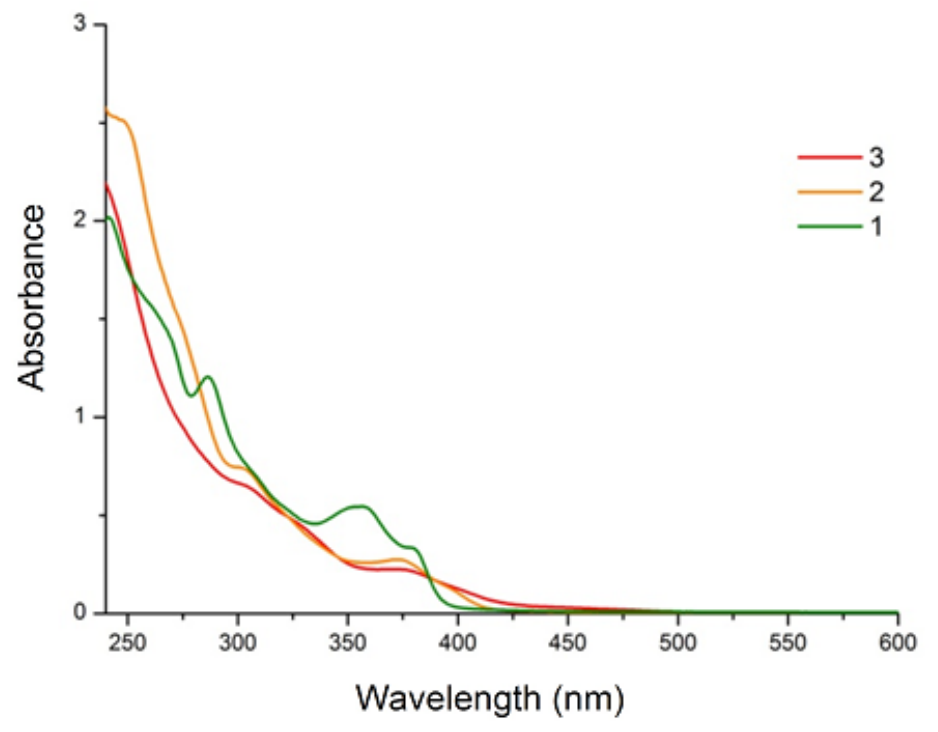


Figure 3. Absorption spectra of the complexes 1-3 in dichloromethane solution $\left(10^{-4} \mathrm{M}\right)$ at room temperature.

On the basis of DFT studies for the calculated absorption spectra (vide infra), the bands which appear between 350 and $450 \mathrm{~nm}$, are predominantly assigned to ${ }^{1} \mathrm{IL},{ }^{1} \mathrm{IL}$, ${ }^{1} \mathrm{MLCT},{ }^{1} \mathrm{M}^{\prime} \mathrm{L} \mathrm{CT}^{\prime}-$ based transitions of the complexes 1-3 $\left(\mathrm{L}=\mu\right.$-bpy-2H, $\mathrm{L}^{\prime}=$ bhq-H, M $=$ Pt adjacent to $\mu$-bpy-2H ligand, $\mathrm{M}^{\prime}=\mathrm{Pt}$ adjacent to bhq-H ligands). The relatively intense absorptions below $350 \mathrm{~nm}$ (higher energies) are normally assigned to ligand centered $\pi \rightarrow \pi^{*}$ transitions. In the spectrum of complex 1, the band appearing at $356 \mathrm{~nm}$ (with a shoulder at $385 \mathrm{~nm}$ ) has a mixed ${ }^{1} \mathrm{IL} /{ }^{1} \mathrm{MLCT}$ (predominately ${ }^{1} \mathrm{IL}$ ) character. In contrast, the related band in the spectrum of complex 2 (bearing phosphine donors) is red-shifted, in comparison with that of the complex $\mathbf{1}$, to nearly $372 \mathrm{~nm}$ (with a shoulder at $396 \mathrm{~nm}$ ); this red shift is confirmed by the reduced calculated HOMO-LUMO separation for the complex $\mathbf{2}$ in comparison with that for the complex 1. Situation for the tetranuclear complex $\mathbf{3}$, containing bridging dppm ligands is the same with the corresponding band slightly red-shifted to $379 \mathrm{~nm}$ (with a shoulder at $408 \mathrm{~nm}$ ) as compared with that for 2. Notice that our calculations confirm that in addition to ${ }^{1} \mathrm{MLCT}$ and ${ }^{1} \mathrm{IL}$ transitions (contribution from double roll-over, $\mu$-bpy-2H, ligand), seen for the complexes $\mathbf{1}$ and $\mathbf{2}$, contributions from ${ }^{1} \mathrm{M}^{\prime} \mathrm{L}^{\prime} \mathrm{CT}$ and ${ }^{1} \mathrm{IL}^{\prime}$ transitions (due to the classical cyclometalated part, bhq-H) are also present in the spectrum of complex 3, with ${ }^{1} \mathrm{MLCT}$ and ${ }^{1} \mathrm{M}^{\prime} \mathrm{L}$ 'CT transitions having main contribution in the corresponding low energy bands of complex $\mathbf{3}$. 
Table 1. Photophysical data of the complexes 1-3.

\begin{tabular}{|c|c|c|c|c|c|c|}
\hline Complex & $\lambda_{\text {abs }} / \mathrm{nm}\left(\varepsilon / 10^{4} \cdot \mathrm{cm}^{-1} \cdot \mathrm{M}^{-1}\right)$ & & $\lambda_{\mathrm{em}} / \mathrm{nm}\left(\lambda_{\mathrm{exc}} / \mathrm{nm}\right)$ & & $\phi^{\mathrm{c}}$ & $\tau^{\mathrm{d}}(\mu \mathrm{S})$ \\
\hline & & Solution (RT) ${ }^{\text {a }}$ & Solid (RT) & Solid (LT) ${ }^{\mathrm{b}}$ & & \\
\hline 1 & $\begin{array}{c}385(0.237), 356(0.544), \\
286(1.206 .)\end{array}$ & $\begin{array}{c}491,527^{\max } \\
570^{\text {sh }}(345-400)\end{array}$ & $\begin{array}{c}490,526^{\max }, \\
572^{\text {sh }}(345-400)\end{array}$ & $\begin{array}{c}491,527^{\max } \\
570^{\text {sh }}(345-400)\end{array}$ & 0.418 & 10.95 \\
\hline 2 & 372(0.275), 302(0.741), & $588^{\max }(345-400)$ & $587^{\max }(345-400)$ & $\begin{array}{l}499,532^{\max }, 586 \\
\quad(345-400)\end{array}$ & 0.159 & 7.53 \\
\hline 3 & $379(0.216), 305(0.642)$, & $\begin{array}{c}614^{\max }(355-400) \\
353,366^{\max }, \\
385^{\text {sh }}, 408^{\mathrm{sh}}(320)\end{array}$ & $610^{\max }(355-400)$ & $600^{\max }(345-600)$ & 0.271 & 6.56 \\
\hline
\end{tabular}

a Recorded at room temperature.

${ }^{\mathrm{b}}$ Recorded at low temperature.

${ }^{\mathrm{c}}$ Solid state absolute Quantum Yield.

${ }^{\mathrm{d}}$ Lifetime at the peak maxima.

Figure 4 shows the photographic images of complexes 1-3 which are strongly emitting in different conditions when irradiated with a hand-light UV-vis (366 nm) lamp. Upon irradiation by UV light in solution state at room temperature, the complexes $\mathbf{1}, \mathbf{2}$, and $\mathbf{3}$ emit in different colors of green, orange, and red, respectively (see Figure $4 b$ ). As shown in Figures $4 c$ and $4 d$ in solid state at room temperature and low temperature, respectively, they are strongly emitting at room temperature and low temperature (in liquid nitrogen). There are no significant changes in colors of the complexes in solid state as compared with those in solution state.

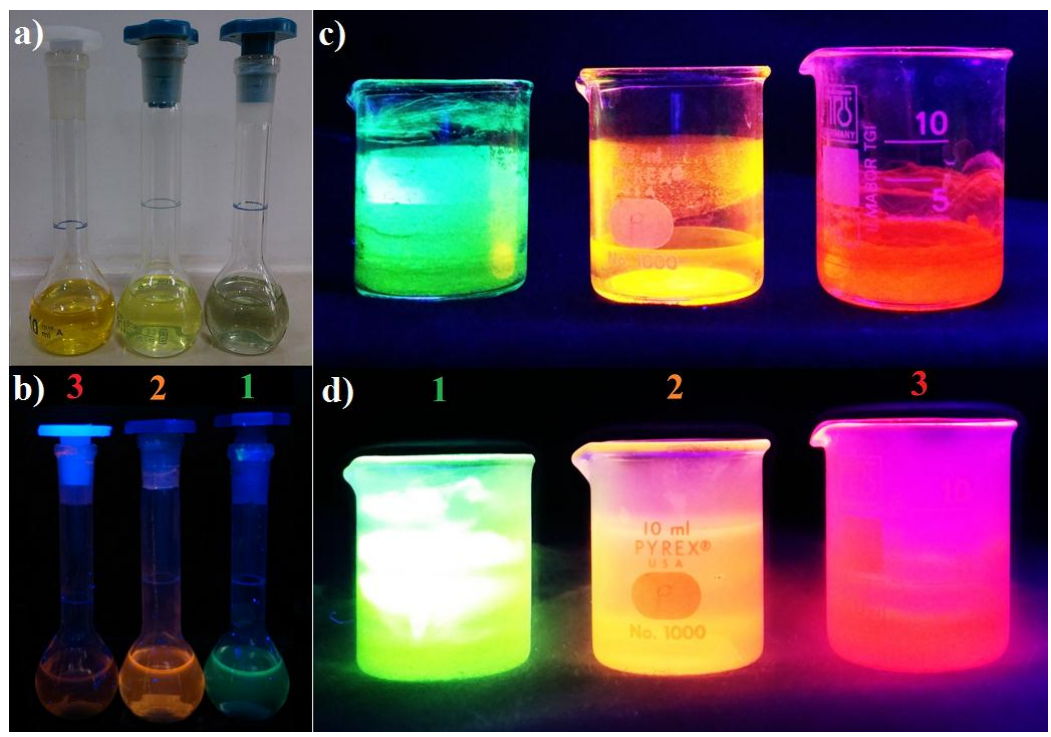


Figure 4. Photographic images of the complexes 1-3 in a) solution state under visible light, b) solution state under UV light, c) room temperature solid state under UV light, and d) low temperature solid state under UV light.

Normalized emission spectra for the complexes 1-3 in dichloromethane solution and solid state at room temperature, upon excitation at 345 to $400 \mathrm{~nm}$, are shown in Figure 5 (see Table 1); as can be seen, the emission spectra of each complex in both solution and solid states have almost the same $\lambda_{\text {exc }} / \mathrm{nm}$ and appearances. The complex 1 shows a bright green luminescent emission band at $491 \mathrm{~nm}$ with a vibronic progression at $527 \mathrm{~nm}$ and a shoulder at approximately $570 \mathrm{~nm}$; this emission is structured (i.e. indicating the presence of a large amount of ligand-centered character in emissive excited state [51]). In comparison with the complex $\mathbf{1}$, the corresponding emission band for complex $\mathbf{2}$, at $588 \mathrm{~nm}$, is considerably red-shifted and is unstructured (i.e. is originating from a metal to ligand charge transfer, MLCT, transition). This MLCT has been set up from $\mathrm{d}$ atomic orbitals of platinum center to $\mathrm{P}_{\pi}$ orbitals of carbons and nitrogens of $\mu$-bpy-2H ligand.
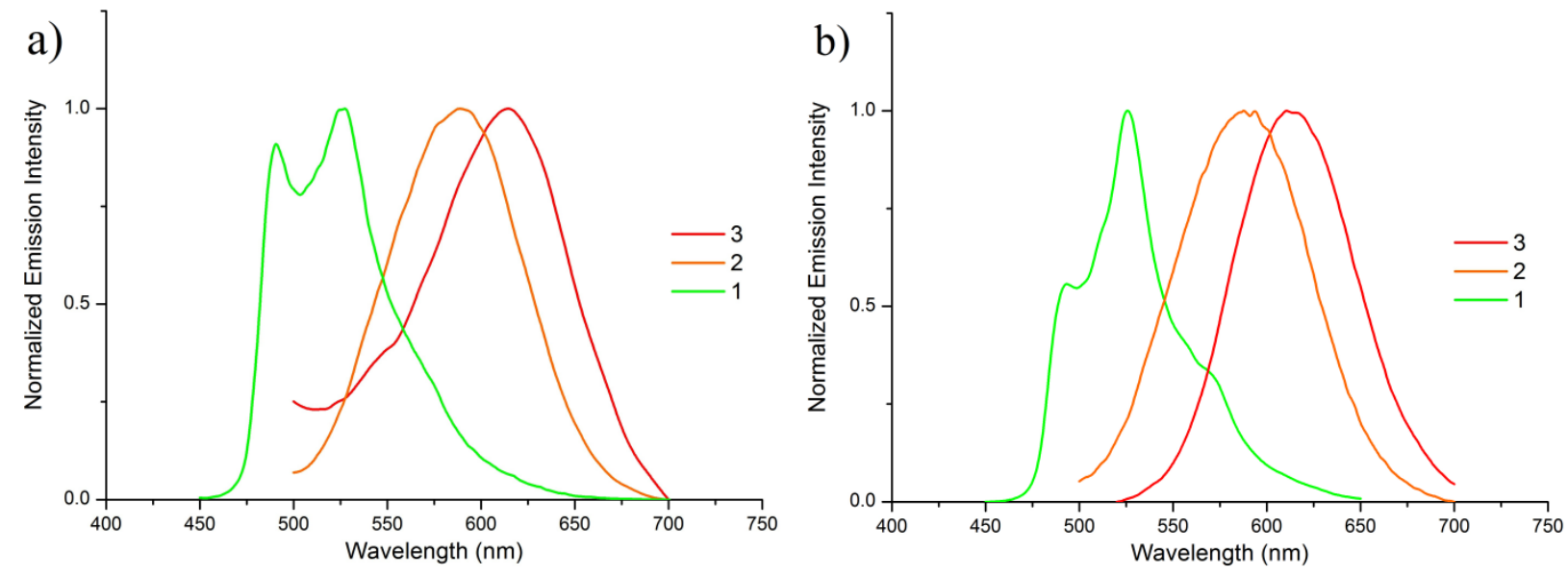
Figure 5. Normalized emission spectra for the complexes 1-3 in a) dichloromethane solution (10$\left.{ }^{4} \mathrm{M}\right)$, and b) solid state, at room temperature.

The emission band for complex 3 is appeared near $614 \mathrm{~nm}$ which is red shifted as compared to that for the complex 2 (at $588 \mathrm{~nm}$ ); this is attributed to the existence of two additional bhq-H ligands in the former complex (having extended $\pi$ conjugation system) relative to the latter complex. Once again, the emission band for complex $\mathbf{3}$ is unstructured, originating from the two different charge transfers MLCT (of the $\mu$-bpy-2H ligand) and $\mathrm{M}^{\prime} \mathrm{L}^{\prime} \mathrm{CT}$ (of the bhq-H ligands).

The complex 3 also shows a structured emission band (upon excitation at $320 \mathrm{~nm}$ ) appearing at $353 \mathrm{~nm}$ with a vibronic progression at $366 \mathrm{~nm}$ and two shoulders at 385 and $408 \mathrm{~nm}$ (see Figure 6); this observation was detected by monitoring the excitation region $365-320 \mathrm{~nm}$.

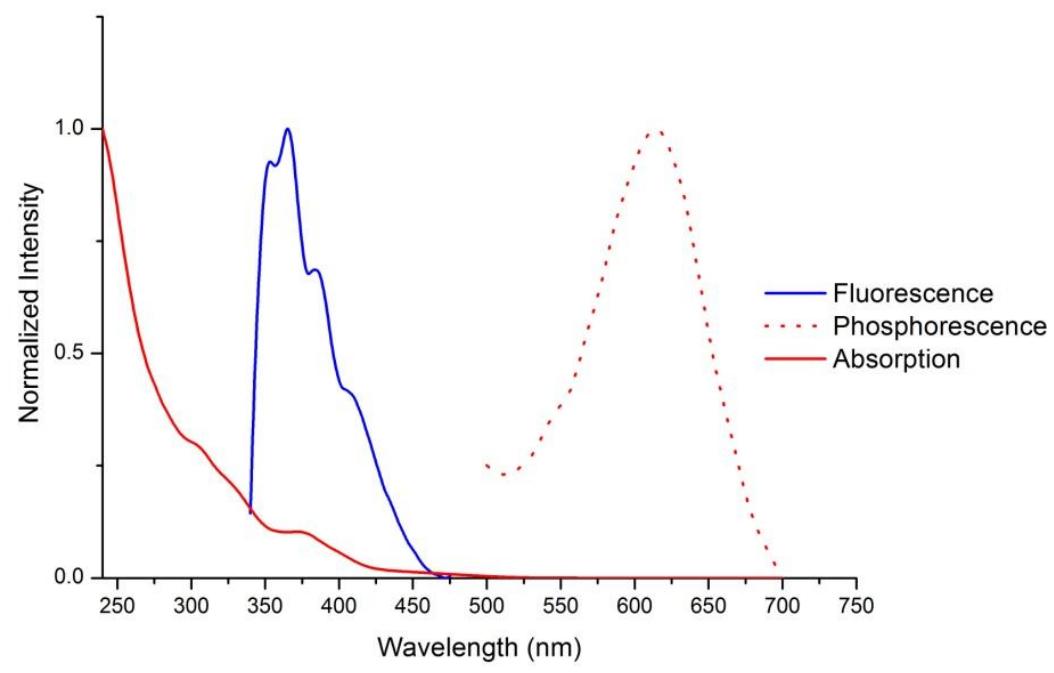

Figure 6. Normalized absorption (red line), fluorescence (blue line), and phosphorescence (red dotted line) spectra for the complex 3 in dichloromethane solution at room temperature. 
On the basis of TD-DFT studies for absorption spectra (vide infra), the transitions around 320 $\mathrm{nm}$ are more related to a $\pi \rightarrow \pi^{*}$ transition in the bhq-H ligands, and thus consistently we did not observe a similar type of emission bands for the other complexes 1-2, having no bhq-H ligands. This additional band observed in spectrum of the complex $\mathbf{3}$, is related to a spin-allowed $\mathrm{S}_{1} \rightarrow \mathrm{S}_{0}$ radiation which has a large $\varepsilon$ (molar absorption coefficient) value in the corresponding region of its absorption spectrum and therefore is a fluorescence radiation in nature. Notice that the unstructured emission band appearing at $614 \mathrm{~nm}$ for the complex 3 (upon excitation at 355-400 $\mathrm{nm}$ ), and also a similar band observing for the other complexes $\mathbf{1}$ or $\mathbf{2}$, is related to a spinforbidden $\mathrm{T}_{1} \rightarrow \mathrm{S}_{0}$ radiation which is partially allowed because of spin orbit coupling. This band, having a very small $\varepsilon$ value in the corresponding region in its absorption spectrum, is therefore a phosphorescence radiation in nature.

Solid state absolute quantum yield (QY) of the complexes 1, 2, and $\mathbf{3}$ were determined and found to be $0.418,0.159$, and 0.271 , respectively. The significantly higher QY value found for the complex $\mathbf{1}$ in this series is probably due to its relatively more rigid structure. Lifetimes at the peak maxima were also measured for the complexes $\mathbf{1}, \mathbf{2}$, and $\mathbf{3}$ in solid state at room temperature and found to be $10.95,7.53$, and $6.56 \mu \mathrm{S}$, respectively. The lifetime values are in the microsecond domain, complying with a triplet excited state with phosphorescence character.

The complexes 1-3 exhibit luminescence in the solid state at low temperature ( $77 \mathrm{~K})$ as shown in Figure 7. As can be seen in Figure 7 and table 1, there is no change in the structure and wavelength of complex $\mathbf{1}$ emission band showing that this complex is rigid enough even at room temperature. For the complex 2 , upon cooling to $77 \mathrm{~K}$ the emission band becomes structured with a significant blue shift at the peak maxima $(55 \mathrm{~nm})$. The emission band of complex 2 shows a dual emission, a higher energy structured emission band with $\lambda_{\max } 532 \mathrm{~nm}$ and minor 
contribution of a lower energy emission band centered at $586 \mathrm{~nm}$.[52] For the complex 3, the emission band shape at $77 \mathrm{~K}$ is similar to its $298 \mathrm{~K}$ band with a slight blue shift $(10 \mathrm{~nm})$, confirming that ${ }^{3} \mathrm{MLCT}$ is still the main character in the emissive state. These observations show a rigidochromism in the structure of complex $\mathbf{3}$ at $77 \mathrm{~K}$. [53]

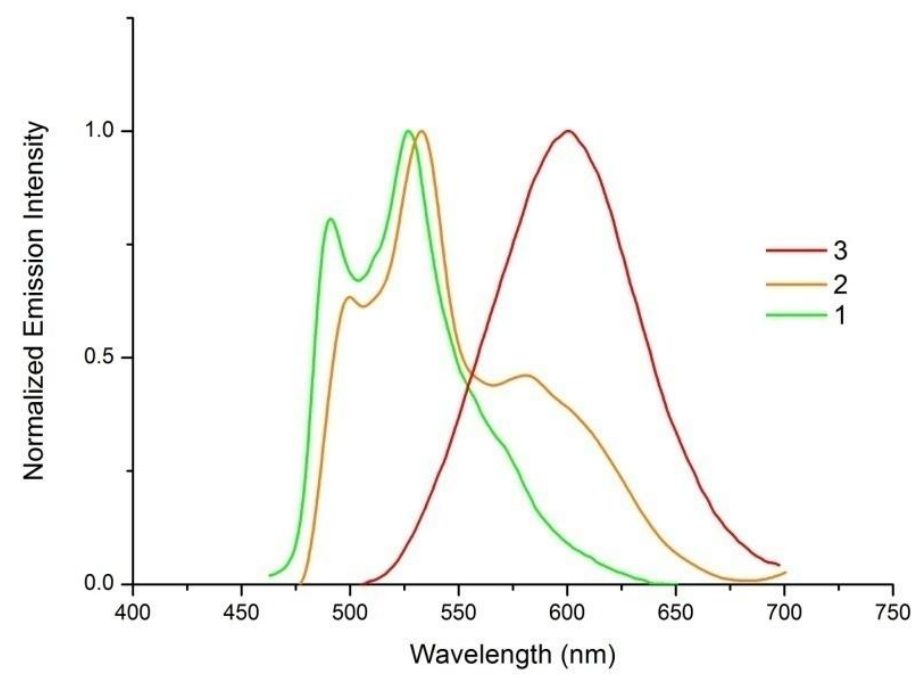

Figure 7. Normalized emission spectra for the complexes 1-3 in solid state, at low temperature (77 K).

Emission spectra of the complexes $\mathbf{2}$ and $\mathbf{3}$ in dichloromethane solution at room temperature at different concentrations $\left(1 \times 10^{-4}, 5 \times 10^{-5}\right.$, and $\left.1 \times 10^{-5} \mathrm{M}\right)$ are shown in Figure 8 . For the both complexes, there are no changes in the structure of emission bands upon lowering the concentration indicating that no aggregation happens even in their concentrated solutions. [54] 


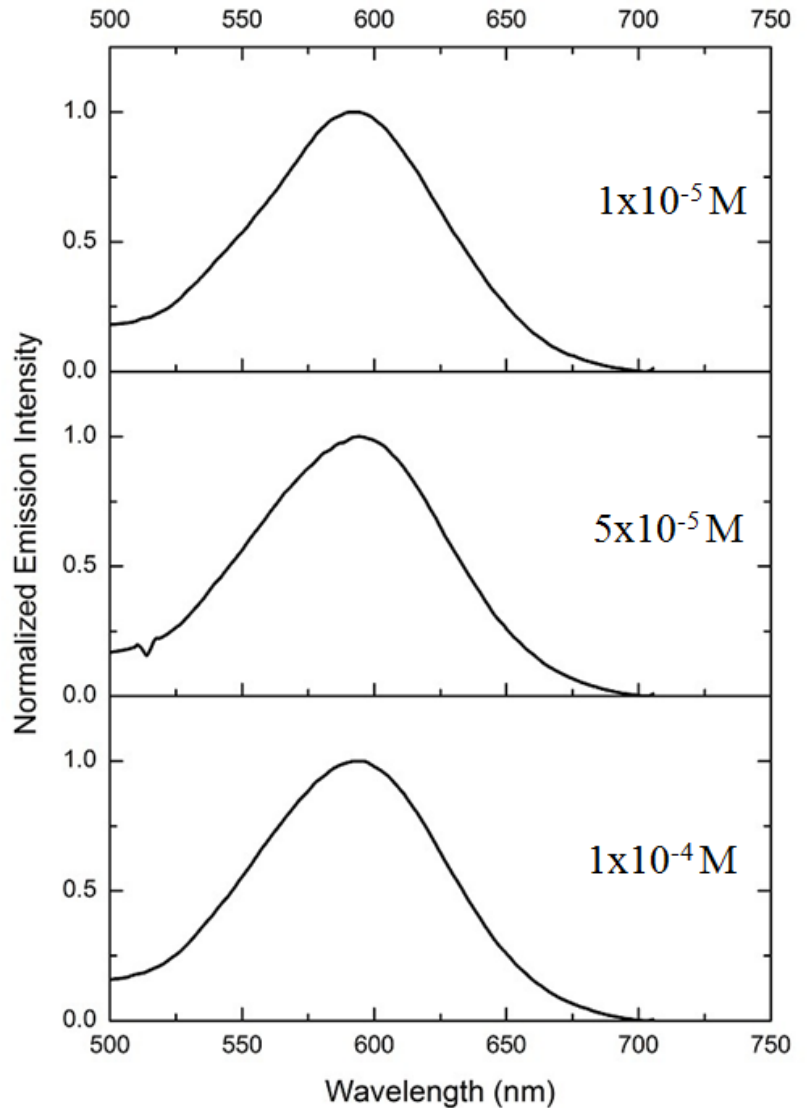

(a)

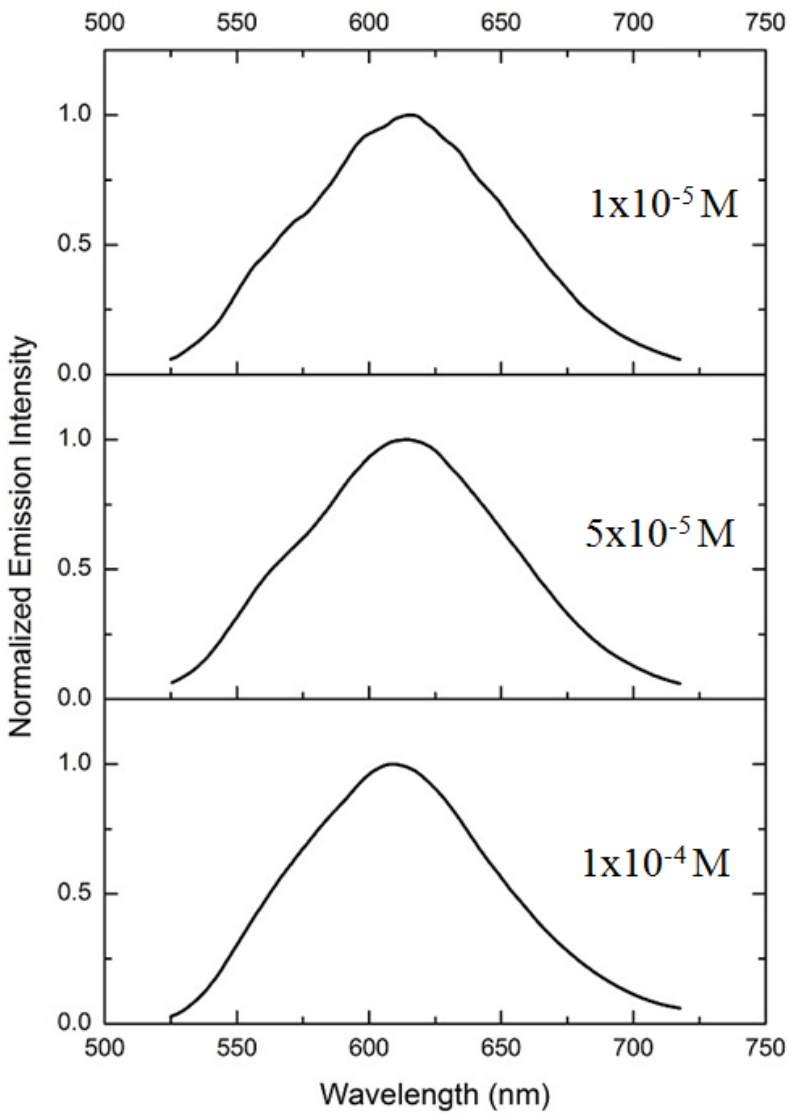

(b)

Figure 8. Emission spectra of the complexes $\mathbf{2}$ (a) and $\mathbf{3}$ (b) in dichloromethane solution at room temperature at different concentrations $\left(1 \times 10^{-4}, 5 \times 10^{-5}\right.$, and $\left.1 \times 10^{-5} \mathrm{M}\right)$ at wavelength range of $345-400 \mathrm{~nm}$.

\subsection{DFT Investigation}

Structures of the complexes $\mathbf{1 - 3}$ in dichloromethane solution were fully optimized using DFT method with the B3LYP/LANL2DZ basis set level (Figure S1-S3). Selected calculated bond lengths and angles of optimized geometries (singlet and triplet states) of the complexes $\mathbf{1}, \mathbf{2}$, and 3 are given in Table S1, Table S2, and Table S3, respectively, at the B3LYP/6-31G(d) level (LANL2DZ potential for Pt). 
In the complex 3, Pt-P bond lengths trans to $\mathrm{C}$ ligating atom of $\mu$-bpy-2H (e.g. Pt1-P24 = $2.42308 \mathrm{~A}^{\circ}$ ) are considerably longer than those of Pt-P bonds trans to $\mathrm{C}$ ligating atom of bhq-H (e.g. Pt83-P82 $=2.40553 \mathrm{~A}^{\circ}$ ) showing that the trans influence of metalated $\mathrm{C}$ of $\mu-\mathrm{bpy}-2 \mathrm{H}$ is higher than that of metalated $\mathrm{C}$ of bhq-H.

Atomic charges of platinum centers of the complexes 1-3 were obtained using a natural bond orbital (NBO) analysis and the results are summarized in Table 2. Pt charge values for both the complexes $\mathbf{2}$ and $\mathbf{3}$ are negative (with the latter being more negative than the former) as compared to those for the complex 1 having positive charge values (Table 2). In the complex $\mathbf{1}$, electron withdrawing oxygen atoms of DMSO ligands cause electron density on the Pt centers to decrease to the extent that their charges become positive. However, in the complexes $\mathbf{2 - 3}$, the existence of phosphorus ligating atoms (each one being stronger $\sigma$-donor as compared to $\mathrm{S}$ ligating atom of each of the DMSO ligands in 1) make the electron density on the Pt centers to comparatively increase to the extent that their charges become negative.

Table 2. NPA (natural population analysis) charges on Pt atoms of the complexes 1-3.

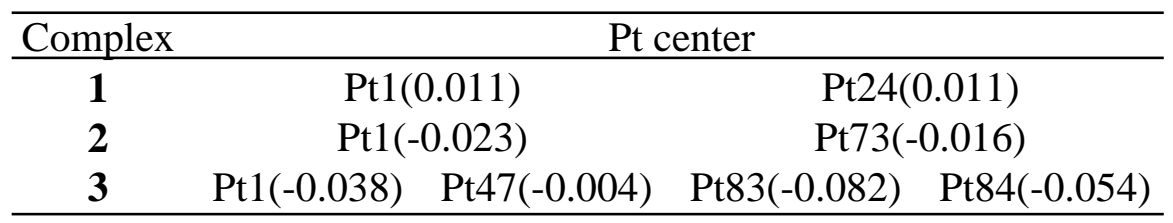

Energies of selected relevant molecular orbitals of the complexes 1-3 and their compositions in the singlet state, and in the triplet state LSOMO (lowest singly occupied molecular orbital) and HSOMO (highest singly occupied molecular orbital), are shown in Table 3. Comparative energy level diagram of the complexes 1-3 are shown in Figure 9. 
HOMO-LUMO gap in the complex $\mathbf{1}$ is equal to $4.149 \mathrm{eV}$; $\mathrm{d}_{\mathrm{yz}}$ and $\mathrm{d}_{\mathrm{xz}}$ atomic orbitals of the $\mathrm{Pt}$ atoms have the maximum contribution coefficient in the HOMO with $\mathrm{P}_{z}$ atomic orbitals of carbons and nitrogens of $\mu$-bpy- $2 \mathrm{H}$ ligand having lower ranks. Besides, the LUMO is predominantly localized on $\mathrm{P}_{\pi}$ (i.e. $\mathrm{P}_{z}$ ) orbitals of $\mathrm{C}$ and $\mathrm{N}$ atoms of the $\mu$-bpy-2H ligand.

For the complex 2, HOMO-LUMO gap is $4.130 \mathrm{eV}$, which is significantly smaller than that in $\mathbf{1}$ (being $4.149 \mathrm{eV}$ ); in $\mathbf{2}, \mathrm{d}_{\mathrm{xy}}$ and $\mathrm{d}_{\mathrm{x}}{ }^{2}-\mathrm{y}^{2}$ atomic orbitals on the Pt centers have maximum contribution coefficient in the HOMO, while $\mathrm{P}_{\mathrm{y}}$ atomic orbitals of $\mathrm{C}$ and $\mathrm{N}$ atoms of $\mu$-bpy-2H ligand and also $\mathrm{d}_{\mathrm{xz}}$ and $\mathrm{d}_{\mathrm{yz}}$ atomic orbitals on the Pt centers have the lower ranks. In this complex, $\mathrm{P}_{\pi}$ orbitals of $\mathrm{C}$ and $\mathrm{N}$ atoms of the $\mu$-bpy- $2 \mathrm{H}$ ligand (i.e. $\mathrm{P}_{y}$ ) predominantly exist in the LUMO.

HOMO-LUMO gap in the complex $\mathbf{3}(3.917 \mathrm{eV})$ is smaller than those in $\mathbf{1}$ and $\mathbf{2}$. In this tetranuclear complex, HOMO and HOMO-1 levels are organized from combination of $\mathrm{d}_{\mathrm{x}}^{2}-\mathrm{y}^{2}$ and $\mathrm{d}_{\mathrm{yz}}$ atomic orbitals (on the Pt centers adjacent to bhq-H ligands, i.e. Pt83 and Pt84) and $\mathrm{P}_{\pi}$ orbitals (i.e. $\mathrm{P}_{\mathrm{x}}$ and $\mathrm{P}_{\mathrm{z}}$ ) of bhq-H ligands. HOMO-3 and HOMO-4 levels are formed from combination of $\mathrm{d}_{\mathrm{x}}^{2}-\mathrm{y}^{2}, \mathrm{~d}_{\mathrm{xz}}$, and $\mathrm{d}_{\mathrm{yz}}$ atomic orbitals on the Pt centers adjacent to bhq-H ligands, whereas HOMO-5 and HOMO-6 are composed of $d_{x z}, d_{y z}$, and $d_{x y}$ atomic orbitals on the Pt centers adjacent to $\mu$-bpy-2H ligand (i.e. Pt1 and Pt47). LUMO and LUMO+1 are composed of $\mathrm{P}_{\pi}$ orbitals of $\mathrm{C}$ and $\mathrm{N}$ atoms of the bhq-H ligands (i.e. $\mathrm{P}_{\mathrm{x}}$ and $\mathrm{P}_{\mathrm{z}}$ ) and LUMO+2 is combination of $\mathrm{P}_{\pi}$ orbitals of $\mathrm{C}$ and $\mathrm{N}$ atoms of the $\mu$-bpy-2H ligand (i.e. $\mathrm{P}_{\mathrm{z}}$ and $\mathrm{P}_{\mathrm{y}}$ ). Plots of the important MO orbitals for each of the complexes 1-3 are provided in Figure 10. 
Table 3. Energies of selected molecular orbitals of the complexes 1-3 and their compositions in the singlet and triplet states.

\begin{tabular}{|c|c|c|c|c|c|c|c|c|c|c|c|}
\hline \multirow[b]{3}{*}{ State } & \multirow[b]{3}{*}{ MO } & \multicolumn{5}{|c|}{ Complex 1} & \multicolumn{5}{|c|}{ Complex 2} \\
\hline & & \multirow{2}{*}{$\begin{array}{c}\text { Energy } \\
(\mathrm{eV})\end{array}$} & \multicolumn{4}{|c|}{ Components $(\%)$} & \multirow{2}{*}{$\begin{array}{c}\text { Energy } \\
(\mathrm{eV})\end{array}$} & \multicolumn{4}{|c|}{ Components $(\%)$} \\
\hline & & & $\mathrm{Pt}$ & $\mu$-bpy-2H & $\mathrm{Me}$ & $\overline{\mathrm{dmso}}$ & & $\mathrm{Pt}$ & $\mu$-bpy-2H & $\mathrm{Me}$ & $\mathrm{dppm}$ \\
\hline \multirow[t]{10}{*}{ Singlet } & $\mathrm{LUMO}+4$ & +0.321 & 33 & 29 & 0 & 38 & -0.794 & 2 & 1 & 0 & 97 \\
\hline & LUMO+3 & -0.068 & 29 & 22 & 10 & 39 & -0.941 & 2 & 5 & 0 & 93 \\
\hline & LUMO+2 & -0.706 & 10 & 64 & 0 & 27 & -0.971 & 4 & 4 & 0 & 92 \\
\hline & LUMO+1 & -1.261 & 11 & 72 & 0 & 17 & -1.030 & 11 & 58 & 0 & 30 \\
\hline & LUMO & -1.833 & 5 & 92 & 1 & 2 & -1.589 & 5 & 90 & 1 & 4 \\
\hline & HOMO & -5.982 & 44 & 52 & 0 & 4 & -5.719 & 43 & 52 & 0 & 5 \\
\hline & HOMO-1 & -6.098 & 89 & 6 & 4 & 1 & -5.867 & 86 & 7 & 4 & 4 \\
\hline & HOMO-2 & -6.117 & 94 & 4 & 2 & 0 & -5.883 & 91 & 4 & 2 & 4 \\
\hline & HOMO-3 & -6.285 & 83 & 11 & 1 & 5 & -6.042 & 82 & 11 & 1 & 6 \\
\hline & HOMO-4 & -6.320 & 84 & 9 & 2 & 5 & -6.060 & 78 & 9 & 1 & 11 \\
\hline \multirow[t]{2}{*}{ Triplet } & HSOMO & -3.587 & 6 & 91 & 1 & 2 & -3.336 & 7 & 90 & 0 & 3 \\
\hline & LSOMO & -6.096 & 43 & 55 & 0 & 3 & -5.825 & 42 & 54 & 0 & 4 \\
\hline & \multicolumn{11}{|c|}{ Complex $3^{\text {a }}$} \\
\hline \multirow[b]{2}{*}{ State } & & Energy & \multicolumn{7}{|c|}{ Components $(\%)$} & & \\
\hline & MO & $(\mathrm{eV})$ & Pt1 & $\mathrm{Pt} 2$ & $\mu$-bpy-2H & bhq & $\mathrm{Me} 1$ & $\mathrm{Me} 2$ & $\mathrm{dppm}$ & & \\
\hline \multirow[t]{12}{*}{ Singlet } & LUMO+4 & -1.158 & 0 & 3 & 1 & 80 & 0 & 0 & 16 & & \\
\hline & LUMO+3 & -1.197 & 1 & 3 & 0 & 48 & 0 & 0 & 49 & & \\
\hline & LUMO+2 & -1.625 & 5 & 0 & 89 & 0 & 1 & 0 & 5 & & \\
\hline & LUMO+1 & -1.668 & 0 & 3 & 0 & 93 & 0 & 0 & 4 & & \\
\hline & LUMO & -1.674 & 0 & 3 & 0 & 80 & 0 & 0 & 17 & & \\
\hline & HOMO & -5.610 & 0 & 30 & 0 & 65 & 0 & 0 & 5 & & \\
\hline & HOMO-1 & -5.617 & 0 & 30 & 0 & 47 & 0 & 0 & 23 & & \\
\hline & HOMO-2 & -5.737 & 43 & 0 & 52 & 0 & 0 & 0 & 5 & & \\
\hline & HOMO-3 & -5.845 & 0 & 82 & 0 & 6 & 0 & 3 & 9 & & \\
\hline & HOMO-4 & -5.852 & 0 & 85 & 0 & 7 & 0 & 2 & 6 & & \\
\hline & HOMO-5 & -5.907 & 83 & 0 & 9 & 0 & 4 & 0 & 4 & & \\
\hline & HOMO-6 & -5.919 & 89 & 0 & 6 & 0 & 2 & 0 & 3 & & \\
\hline \multirow[t]{2}{*}{ Triplet } & HSOMO & -3.370 & 3 & 0 & 91 & 0 & 0 & 0 & 6 & & \\
\hline & LSOMO & -5.608 & 0 & 30 & 0 & 65 & 0 & 0 & 5 & & \\
\hline
\end{tabular}

${ }^{\mathrm{a}}$ In the complex 3, Pt $1=$ platinum atoms adjacent to $\mu$-bpy- $2 \mathrm{H}, \mathrm{Pt} 2=$ platinum atoms adjacent to bhq- $\mathrm{H}, \mathrm{Me} 1=$ Me groups adjacent to $\mathrm{Pt} 1, \mathrm{Me} 2=$ Me groups adjacent to $\mathrm{Pt} 2$. 


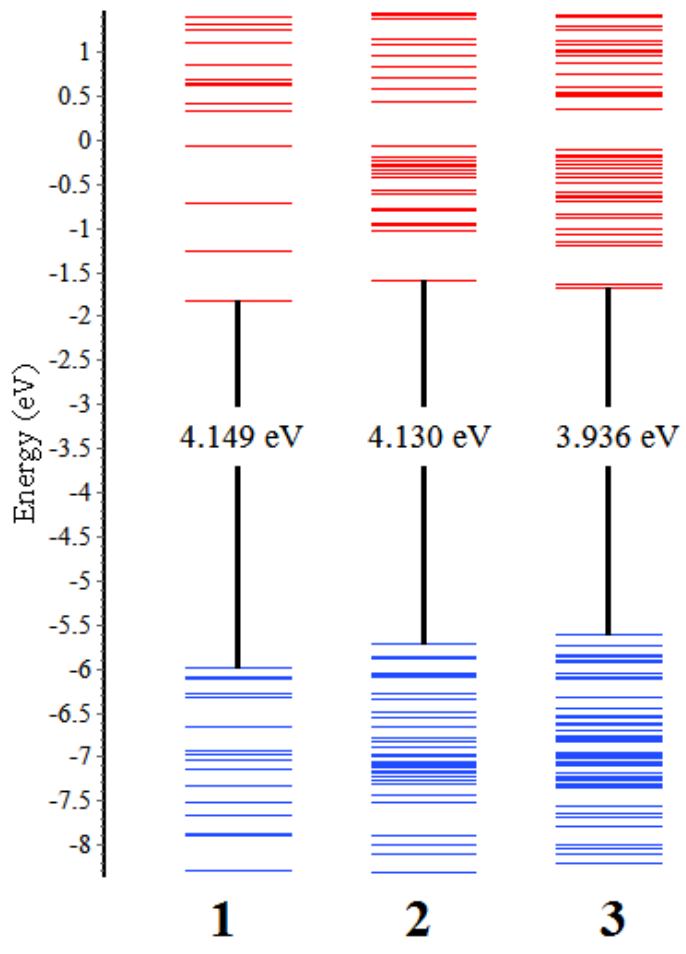

Figure 9. Energy level diagram for calculated molecular orbitals of the complexes 1-3. 

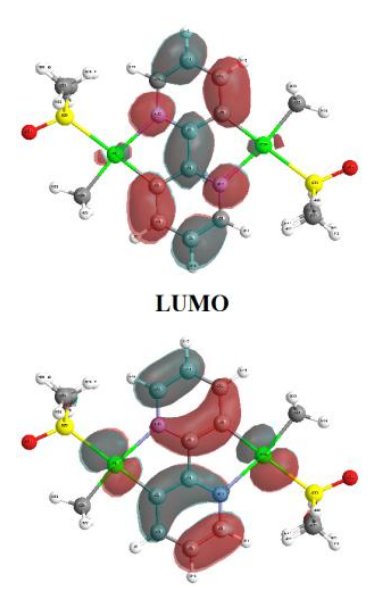

номо

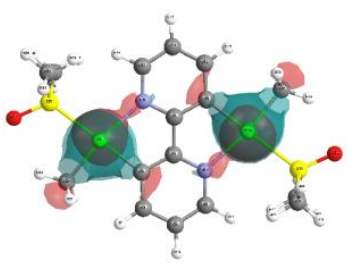

HOMO-1

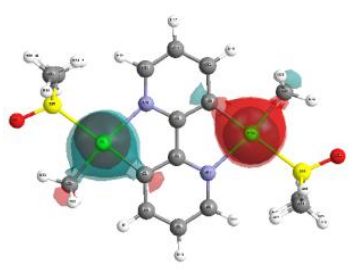

HOMO-2

1
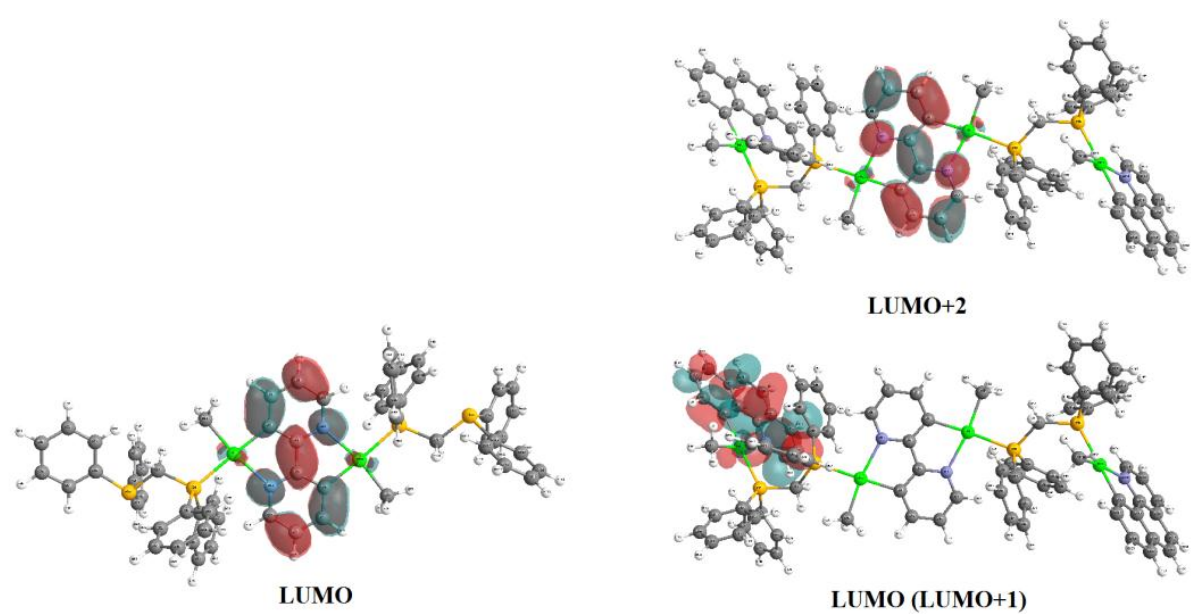

LUMO+2
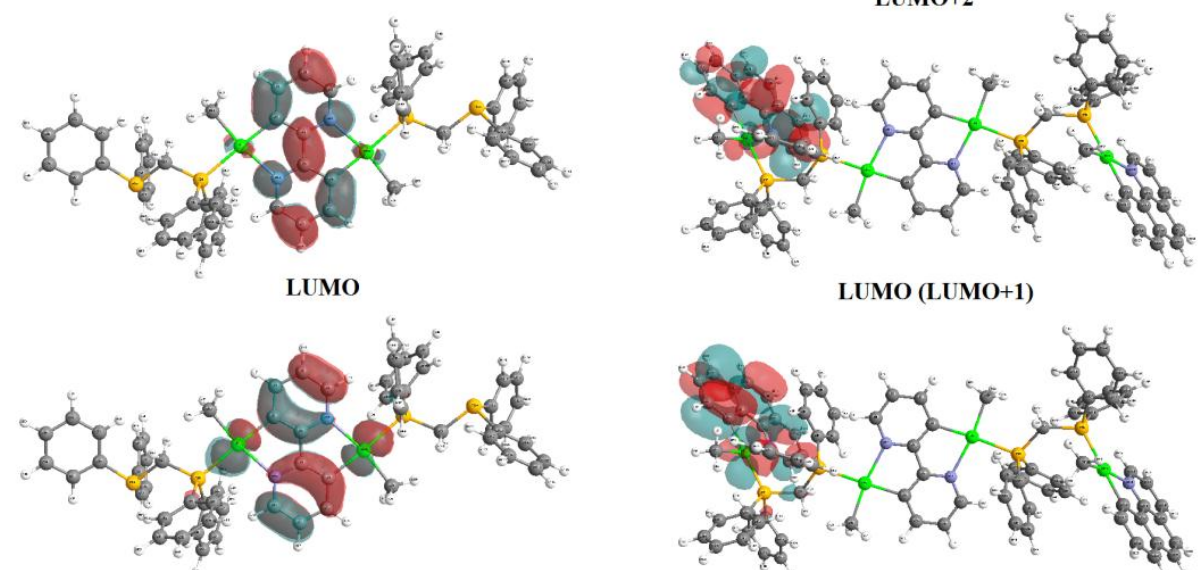

номо

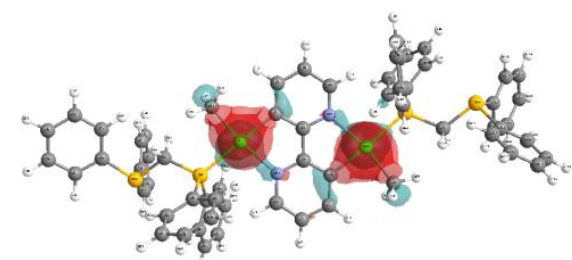

HOMO-1

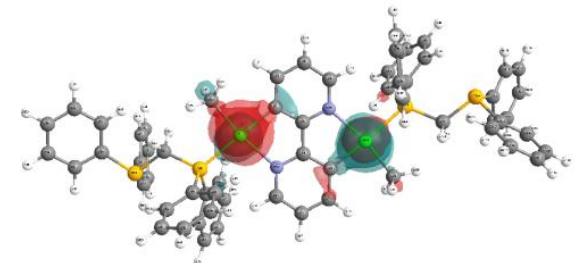

HOMO-2

2

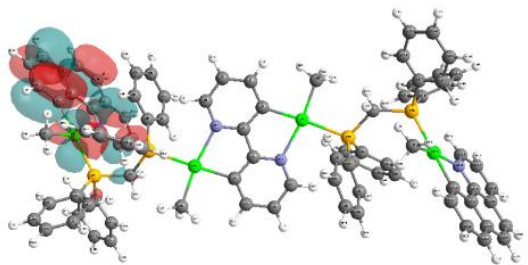

HOMO (HOMO-1)

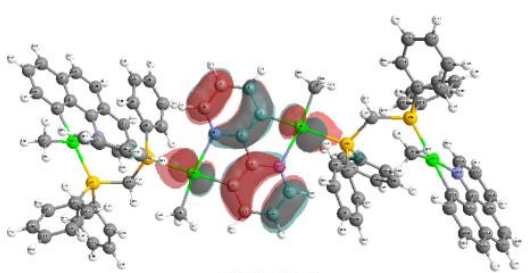

HOMO-2

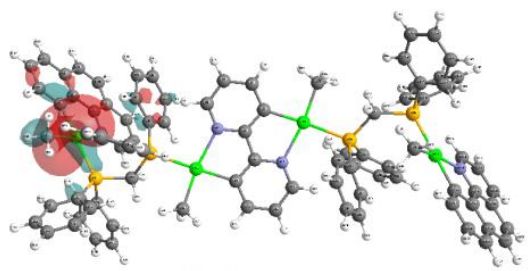

HOMO-3 (HOMO-4)

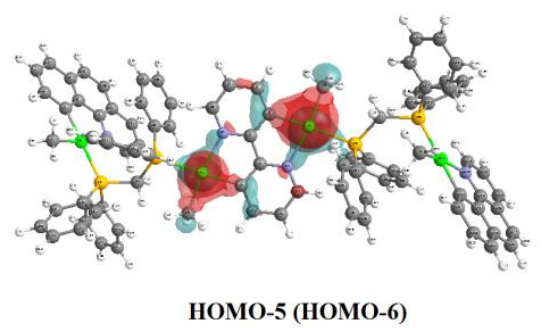

3

Figure 10. Plots of important MO orbitals for the complexes 1-3. 
To gain further insights into the nature of the absorption characters and electronic transitions of the complexes 1-3 in dichloromethane, TD-DFT calculations were performed for calculation of the absorption spectra (see Figure 11) and the resulting data, showing nature and the corresponding wavelengths for the transitions involving in the complexes $\mathbf{1 - 3}$, are collected in Table 4. As can be seen, all the peaks appearing for the complex $\mathbf{1}$ have a mixed IL/MLCT character dominating by the IL character. For the complex 2, however, the peaks at 363 and 357 $\mathrm{nm}$ have predominantly MLCT character, while for the peak at $334 \mathrm{~nm}$ various contributions of transitions like IL, MLCT, $\mathrm{L}_{2}{ }_{2} \mathrm{LCT}$, and $\mathrm{L}_{1}{ }_{1} \mathrm{LCT}$ are observed. For the complex $\mathbf{3}$, the transitions are divided into two categories: 1- transitions in the roll-over cyclometalated moieties, $\mu$-bpy$2 \mathrm{H}$, and 2- transitions in the classical cyclometalated moieties, bhq- $\mathrm{H}$. For the category 1 , the peaks are appearing at 365,356 , and $335 \mathrm{~nm}$ which are mainly constituted of MLCT/IL transitions. However, the peak for the category 2 is appearing at $379 \mathrm{~nm}$, mainly having $\mathrm{M}^{\prime} \mathrm{L}^{\prime} \mathrm{CT} / \mathrm{IL} \mathrm{L}^{\prime}$ characters. 

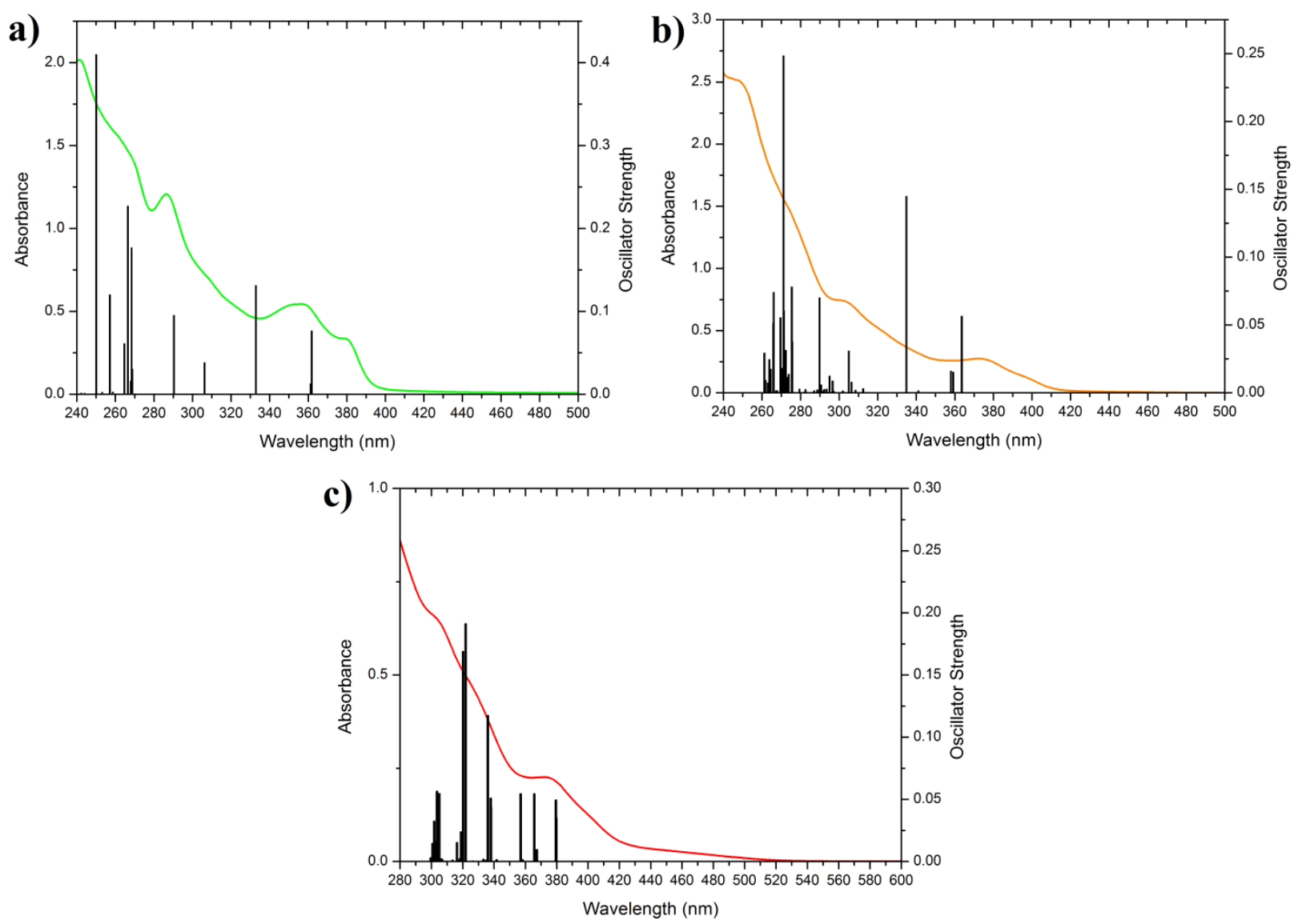

Figure 11. Overlaid experimental absorbance (spectra) and calculated TD-DFT (bars) for the complexes a) 1, b) $\mathbf{2}$, and c) $\mathbf{3}$. 
Table 4. Nature and the corresponding wavelengths for the transitions involving in the complexes 1-3, where $\mathrm{M}=\mathrm{Pt}$ atoms adjacent to $\mu$-bpy-2H ligand, $\mathrm{M}^{\prime}=\mathrm{Pt}$ atoms adjacent to bhq$\mathrm{H}$ ligands, $\mathrm{L}=\mu$-bpy- $2 \mathrm{H}, \mathrm{L}^{\prime}=\mathrm{bhq}-\mathrm{H}, \mathrm{L}_{1}{ }_{1}=\mathrm{dppm}, \mathrm{L}_{2}=\mathrm{Me}$.

\begin{tabular}{|c|c|c|c|}
\hline Complex & Calculated $\lambda(\mathrm{nm})(f)$ & Transitions(Contribution) & Assignment \\
\hline \multirow[t]{5}{*}{1} & \multirow[t]{3}{*}{$361(0.077)$} & $\mathrm{H} \rightarrow \mathrm{L}(0.67)$ & IL/ MLCT \\
\hline & & $\mathrm{H}-4 \rightarrow \mathrm{L}(0.14)$ & IL/ MLCT \\
\hline & & $\mathrm{H}-3 \rightarrow \mathrm{L}(0.13)$ & IL/ MLCT \\
\hline & \multirow[t]{2}{*}{$332(0.131)$} & $\mathrm{H}-4 \rightarrow \mathrm{L}(0.68)$ & IL/ MLCT \\
\hline & & $\mathrm{H} \rightarrow \mathrm{L}(-0.14)$ & IL/ MLCT \\
\hline \multirow[t]{10}{*}{2} & \multirow[t]{3}{*}{$363(0.056)$} & $\mathrm{H} \rightarrow \mathrm{L}(0.64)$ & IL/ MLCT \\
\hline & & $\mathrm{H}-1 \rightarrow \mathrm{L}(-0.21)$ & MLCT \\
\hline & & $\mathrm{H}-2 \rightarrow \mathrm{L}(-0.13)$ & MLCT \\
\hline & \multirow[t]{3}{*}{$357(0.016)$} & $\mathrm{H}-2 \rightarrow \mathrm{L}(0.63)$ & MLCT \\
\hline & & $\mathrm{H}-1 \rightarrow \mathrm{L}(0.22)$ & MLCT \\
\hline & & $\mathrm{H} \rightarrow \mathrm{L}(0.18)$ & $\mathrm{IL} / \mathrm{MLCT}$ \\
\hline & \multirow[t]{4}{*}{$334(0.145)$} & $\mathrm{H}-4 \rightarrow \mathrm{L}(0.61)$ & $\mathrm{IL} / \mathrm{MLCT} / \mathrm{L}{ }_{2} \mathrm{LCT} / \mathrm{L}{ }_{1} \mathrm{LCT}$ \\
\hline & & $\mathrm{H}-3 \rightarrow \mathrm{L}(0.28)$ & $\mathrm{IL} / \mathrm{MLCT} / \mathrm{L}_{2} \mathrm{LCT}$ \\
\hline & & $\mathrm{H}-5 \rightarrow \mathrm{L}(-0.17)$ & L"${ }_{1} \mathrm{LCT} / \mathrm{MLCT}$ \\
\hline & & $\mathrm{H} \rightarrow \mathrm{L}(-0.12)$ & IL/ MLCT \\
\hline \multirow[t]{9}{*}{3} & \multirow[t]{2}{*}{$379(0.049)$} & $\mathrm{H}-1 \rightarrow \mathrm{L}(0.67)$ & $\mathrm{IL}^{\prime} / \mathrm{M}^{\prime} \mathrm{L}^{\prime} \mathrm{CT}$ \\
\hline & & $\mathrm{H}-8 \rightarrow \mathrm{L}(0.15)$ & $\mathrm{IL}^{\prime} / \mathrm{M}^{\prime} \mathrm{L}^{\prime} \mathrm{CT}$ \\
\hline & \multirow[t]{2}{*}{$365(0.054)$} & $\mathrm{H}-2 \rightarrow \mathrm{L}+2(0.63)$ & IL/ MLCT \\
\hline & & $\mathrm{H}-5 \rightarrow \mathrm{L}+2(0.27)$ & MLCT \\
\hline & \multirow[t]{3}{*}{$356(0.054)$} & $\mathrm{H}-5 \rightarrow \mathrm{L}+2(0.58)$ & MLCT \\
\hline & & $\mathrm{H}-6 \rightarrow \mathrm{L}+2(0.27)$ & MLCT \\
\hline & & $\mathrm{H}-2 \rightarrow \mathrm{L}+2(-0.26)$ & IL/ MLCT \\
\hline & \multirow[t]{2}{*}{$335(0.117)$} & $\mathrm{H}-10 \rightarrow \mathrm{L}+2(0.66)$ & IL/ MLCT \\
\hline & & $\mathrm{H}-9 \rightarrow \mathrm{L}+2(0.18)$ & IL/ MLCT \\
\hline
\end{tabular}

In order to investigate the emission properties, optimized structures for $\mathrm{T}_{1}$ states were calculated for the complexes 1, 2 and $\mathbf{3}$ and the relevant molecular orbital plots (as well as those for $\mathrm{S}_{0}$ states, for comparison) are shown in Figures S4, S5, and 12, respectively. For the complex 1 (Figure S4), LSOMO (of $\mathrm{T}_{1}$ state) and HOMO (of $\mathrm{S}_{0}$ state) are both located on $\mu$-bpy-2H and Pt with staying in almost the same levels of energy. Both HSOMO and LUMO are mostly located at $\mu$-bpy-2H with a negligible contribution from $\mathrm{Pt}$, although the former is considerably more stable than the latter. Thus, emission in the complex $\mathbf{1}$ is originated from ${ }^{3} \mathrm{IL}$ excited state $(\mathrm{L}=\mu$ - 
bpy- $2 \mathrm{H}$ ) with having a very small contribution from ${ }^{3} \mathrm{MLCT}$. Natures of the MO's in the complex 2 (Figure S5) are similar to those in the complex 1, although the contribution from Pt in LSOMO (42\%) is now significant and so ${ }^{3}$ MLCT excited state in emission band of the complex 2 is also become important; these results comply well with experimental observation for unstructured emission band of the complex 2 having a considerable amount of ${ }^{3}$ MLCT character in the emissive state.

The ground states LUMO and LUMO+1 for the complex 3 (see Figure 12) have similar structures and energies and are converted to the HSOMO+1 and $\mathrm{HSOMO}+2$ in the triplet excited state. Besides, LSOMO $\left(\mathrm{T}_{1}\right)$ and HOMO $\left(\mathrm{S}_{0}\right)$, having the same energy and structure, both belong to the bhq- $\mathrm{H}$ cycloplatinated chelate (bhq- $\mathrm{H}=60 \%$, $\mathrm{Pt}=30 \%$ ). The LUMO+2 (in $\mathrm{S}_{0}$ ) is converted to the more stabilized HSOMO (in $\mathrm{T}_{1}$ ), both mainly localized on roll-over cycloplatinated part $(\mu-\mathrm{bpy}-2 \mathrm{H}=91 \%)$. We thus come to the conclusion that the emission in $\mathbf{3}$ is originated from different transitions ${ }^{3} \mathrm{IL},{ }^{3} \mathrm{MLCT},{ }^{3} \mathrm{IL}^{\prime},{ }^{3} \mathrm{M}^{\prime} \mathrm{L}{ }^{\prime} \mathrm{CT}$ and ${ }^{3} \mathrm{ML} L \mathrm{LT}(\mathrm{M}=\mathrm{Pt}$ adjacent to $\mu$-bpy-2H, $\mathrm{M}^{\prime}=\mathrm{Pt}$ adjacent to bhq- $\left.\mathrm{H}, \mathrm{L}=\mu-\mathrm{bpy}-2 \mathrm{H}, \mathrm{L}^{\prime}=\mathrm{bhq}-\mathrm{H}\right)$. 


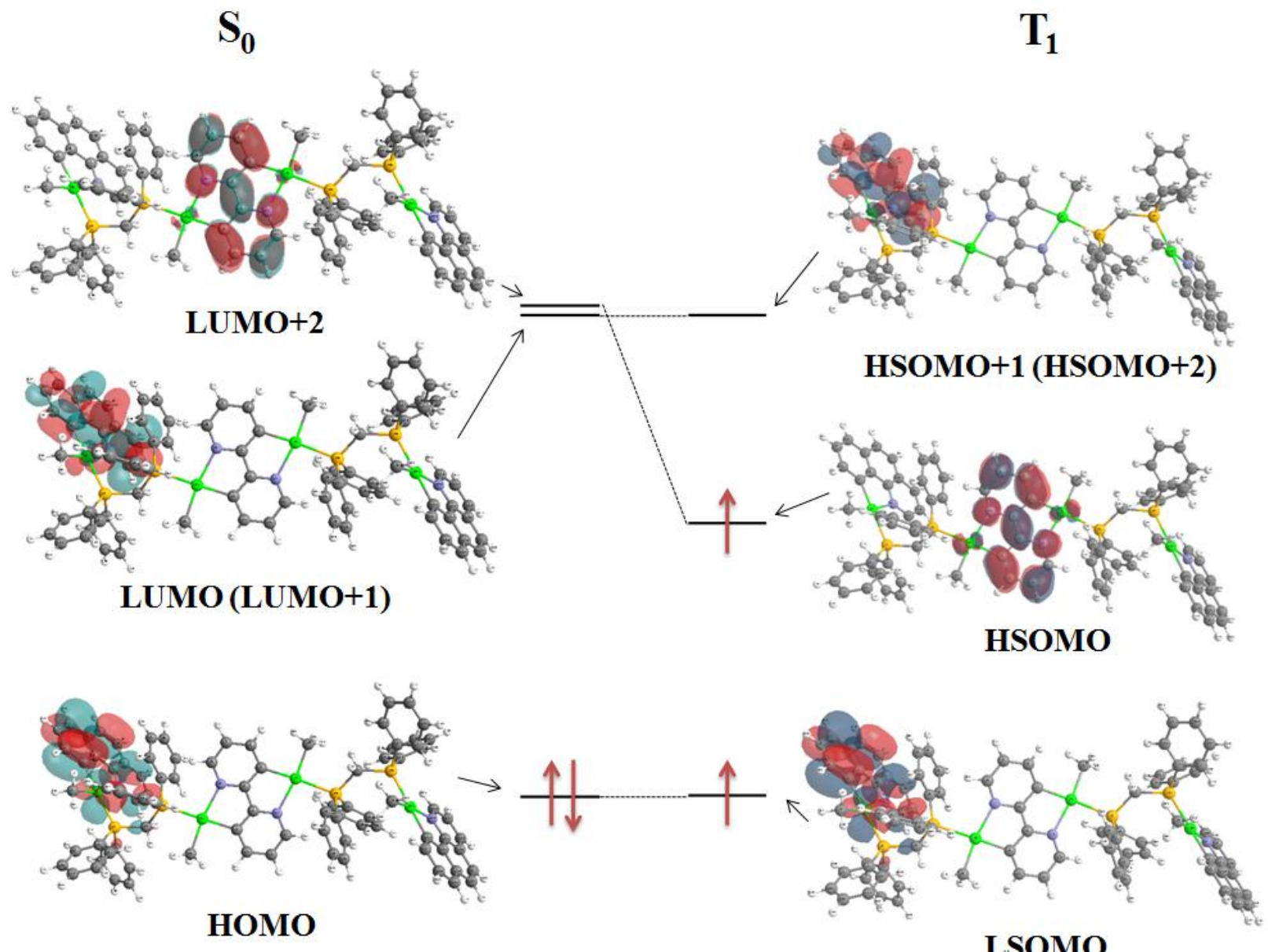

Figure 12. Comparitive MO diagram for computed $\mathrm{S}_{0}$ (left) and $\mathrm{T}_{1}$ (right) states of the complex 3.

\section{Conclusion}

In this work, the absorption and luminescence properties of a new tetranuclear complex [ $\{$ (bhq$\left.\mathrm{H})(\mathrm{Me}) \operatorname{Pt}(\mu-\mathrm{dppm}) \operatorname{Pt}(\mathrm{Me})\}_{2}(\mu-\mathrm{bpy}-2 \mathrm{H})\right], \quad \mathbf{3}$, as well as those of its double rollover cycloplatinated(II) precursor complex $\left[\mathrm{Pt}_{2}(\mu-\mathrm{bpy}-2 \mathrm{H})(\mathrm{Me})_{2}\left(\kappa^{1}-\mathrm{dppm}\right)_{2}\right], \mathbf{2}$, are investigated. The advantage of $\mathbf{3}$ in this photophysical study is that it contains both types of classical cycloplatinated(II) and double roll-over cycloplatinated(II) moieties in one complex suitable for direct comparison of properties of the two types of cycloplatinated species. Besides, each of the 
Pt(II) centers on both complexes $\mathbf{2}$ and $\mathbf{3}$ carries two ancillary ligands with strong ligand fields, a Me ligand and a phosphorus ligating atom (from the bridging dppm ligands), thus increasing the d-d splitting to the extent to prevent any non-radiative interferences; this allows the complexes to emit strongly in solution and solid state at room temperature. The following results, confirmed by DFT calculations, worth noting:

1- All the complexes $\mathbf{1 - 3}$ have a common $\mu$-bpy-2H ligand acting as chromophore. In the complex 3 , in addition to $\mu$-bpy-2H ligand, bhq- $\mathrm{H}$ ligands are also chromophore with extended $\pi$-delocalization system.

2- Band shapes of the green emission of complex $\mathbf{1}$ in both solution and solid states (Figure 5) describe them to be structured, confirming that the emissions have large amount of ligand center character (IL). However, upon displacement of dmso in $\mathbf{1}$ by dppm, to form $\mathbf{2}$ and finally $\mathbf{3}$, all the $\operatorname{Pt}(\mathrm{II})$ centers become more negative, as compared to those in $\mathbf{1}$ (the $\sigma$-donor ability of $\mathrm{P}$ ligating atom is stronger than that of dmso), and the center of transitions in $\mathbf{2}$ and $\mathbf{3}$ are changed to MLCT transition.

3- Lifetime values at the peak maxima for the complexes 1-3 (in solid state at room temperature) were in microsecond domain complying with a triplet excited state with phosphorescence character.

4- The complex 3 shows a different behavior in emission band wavelength and shape upon excitation at $320 \mathrm{~nm}$ (See Figure 6). On the basis of DFT studies for absorption spectra, the transitions around $320 \mathrm{~nm}$ are more related to a $\pi \rightarrow \pi^{*}$ transition in the bhq- $\mathrm{H}$ ligands. Its emission occurs at $353 \mathrm{~nm}$ with a vibronic progression at $366 \mathrm{~nm}$. This band is fluorescence in nature because the corresponding region of this band in its absorption spectrum is related to the spin-allowed bands with large $\varepsilon$ value. 


\section{Acknowledgment}

We thank the Iran National Science Foundation (Grant no.93035108), and the Shiraz University

Research Council for financial support. 


\section{References}

[1] J. Dehand, M. Pfeffer, Coord. Chem. Rev . 18 (1976) 327-352.

[2] M.I. Bruce, Angew. Chem. Int. Ed. Engl., 16 (1977) 73-86.

[3] E.C. Constable, Polyhedron, 3 (1984) 1037-1057.

[4] G.R. Newkome, W.E. Puckett, V.K. Gupta, G.E. Kiefer, Chem. Rev., 86 (1986) 451-489.

[5] I. Omae, Coord. Chem. Rev., 83 (1988) 137-167.

[6] J.T. Singleton, Tetrahedron, 59 (2003) 1837-1857.

[7] J. Dupont, C.S. Consorti, J. Spencer, Chem. Rev., 105 (2005) 2527-2572.

[8] L.N. Lewis, N. Lewis, J. Am. Chem. Soc., 108 (1986) 7228-7231.

[9] J. Dupont, M. Pfeffer, J. Spencer, Eur. J. Inorg. Chem., 2001 (2001) 1917-1927.

[10] J.S. Fossey, C.J. Richards, Organometallics, 23 (2004) 367-373.

[11] M. Frezza, Q.P. Dou, Y. Xiao, H. Samouei, M. Rashidi, F. Samari, B. Hemmateenejad, J. Med. Chem., 54 (2011) 6166-6176.

[12] P. Espinet, M.A. Esteruelas, L.A. Oro, J.L. Serrano, E. Sola, Coord. Chem. Rev., 117 (1992) 215-274.

[13] L. Cola, Chem. Commun., (2004) 1774-1775.

[14] C.M. Che, C.C. Kwok, S.W. Lai, A.F. Rausch, W.J. Finkenzeller, N. Zhu, H. Yersin, Chem. Eur. J., 16 (2010) 233-247.

[15] J. Gareth Williams, S. Develay, D.L. Rochester, L. Murphy, Coord. Chem. Rev., 252 (2008) 2596-2611.

[16] J.R. Berenguer, Á. Díez, E. Lalinde, M.T. Moreno, S. Ruiz, S. Sánchez, Organometallics, 30 (2011) 5776-5792. 
[17] J.s.R. Berenguer, E. Lalinde, M.T. Moreno, S. Sánchez, J. Torroba, Inorg. Chem., 51 (2012) 11665-11679.

[18] J. Liu, C.-H. Leung, A.L.-F. Chow, R.W.-Y. Sun, S.-C. Yan, C.-M. Che, Chem. Commun., 47 (2011) 719-721.

[19] C.K. Koo, L.K.Y. So, K.L. Wong, Y.M. Ho, Y.W. Lam, M.H.W. Lam, K.W. Cheah, C.C.W. Cheng, W.M. Kwok, Chem. Eur. J., 16 (2010) 3942-3950.

[20] V.W.W. Yam, R.P.L. Tang, K.M.C. Wong, X.X. Lu, K.K. Cheung, N. Zhu, Chem. Eur. J., 8 (2002) 4066-4076.

[21] D.-L. Ma, C.-M. Che, S.-C. Yan, J. Am. Chem. Soc., 131 (2008) 1835-1846.

[22] P. Wu, E.L.M. Wong, D.L. Ma, G.S.M. Tong, K.M. Ng, C.M. Che, Chem. Eur. J., 15 (2009) 3652-3656.

[23] J.G. Williams, A. Beeby, E.S. Davies, J.A. Weinstein, C. Wilson, Inorg. Chem., 42 (2003) 8609-8611.

[24] A.F. Van der Ploeg, G. Van Koten, C. Brevard, Inorg. Chem., 21 (1982) 2878-2881.

[25] M. Albrecht, M. Lutz, A.L. Spek, G. van Koten, Nature, 406 (2000) 970-974.

[26] J.W. Slater, D.P. Lydon, J.P. Rourke, J. Organomet. Chem., 645 (2002) 246-255.

[27] J. Buey, L. Díez, P. Espinet, H.-S. Kitzerow, J.A. Miguel, Chem. Mater., 8 (1996) 23752381.

[28] B. Butschke, H. Schwarz, Chem. Sci., 3 (2012) 308-326.

[29] W.A. Wickramasinghe, P.H. Bird, N. Serpone, J. Chem. Soc., Chem. Commun., (1981) 1284-1286.

[30] M. Zuber, F. Pruchnik, Polyhedron, 25 (2006) 2773-2777. 
[31] G. Minghetti, A. Doppiu, A. Zucca, S. Stoccoro, M.A. Cinellu, M. Manassero, M. Sansoni, Chem. Heterocycl. Compd., 35 (1999) 992-1000.

[32] G. Minghetti, S. Stoccoro, M.A. Cinellu, B. Soro, A. Zucca, Organometallics, 22 (2003) 4770-4777.

[33] F. Cocco, M.A. Cinellu, G. Minghetti, A. Zucca, S. Stoccoro, L. Maiore, M. Manassero, Organometallics, 29 (2010) 1064-1066.

[34] B. Butschke, M. Schlangen, D. Schröder, H. Schwarz, Int. J. Mass Spectrom, 283 (2009) 38.

[35] A. Zucca, D. Cordeschi, S. Stoccoro, M.A. Cinellu, G. Minghetti, G. Chelucci, M. Manassero, Organometallics, 30 (2011) 3064-3074.

[36] A. Zucca, M.A. Cinellu, M.V. Pinna, S. Stoccoro, G. Minghetti, M. Manassero, M. Sansoni, Organometallics, 19 (2000) 4295-4304.

[37] A. Zucca, A. Doppiu, M.A. Cinellu, S. Stoccoro, G. Minghetti, M. Manassero, Organometallics, 21 (2002) 783-785.

[38] G.L. Petretto, J.P. Rourke, L. Maidich, S. Stoccoro, M.A. Cinellu, G. Minghetti, G.J. Clarkson, A. Zucca, Organometallics, 31 (2012) 2971-2977.

[39] A. Zucca, D. Cordeschi, L. Maidich, M.I. Pilo, E. Masolo, S. Stoccoro, M.A. Cinellu, S. Galli, Inorg. Chem., 52 (2013) 7717-7731.

[40] L. Maidich, A. Zucca, G.J. Clarkson, J.P. Rourke, Organometallics, 32 (2013) 3371-3375.

[41] F. Cocco, A. Zucca, S. Stoccoro, M. Serratrice, A. Guerri, M.A. Cinellu, Organometallics, 33 (2014) 3414-3424.

[42] A. Zucca, G.L. Petretto, S. Stoccoro, M.A. Cinellu, M. Manassero, C. Manassero, G. Minghetti, Organometallics, 28 (2009) 2150-2159. 
[43] S.M. Nabavizadeh, M.G. Haghighi, A.R. Esmaeilbeig, F. Raoof, Z. Mandegani, S. Jamali, M. Rashidi, R.J. Puddephatt, Organometallics, 29 (2010) 4893-4899.

[44] M.J. Frisch, G.W. Trucks, H.B. Schlegel, G.E. Scuseria, M.A. Robb, J.R. Cheeseman, J.A. Montgomery, Jr., T. Vreven, K.N. Kudin, J.C. Burant, J.M. Millam, S.S. Iyengar, J. Tomasi, V. Barone, B. Mennucci, M. Cossi, G. Scalmani, N. Rega, G.A. Petersson, H. Nakatsuji, M. Hada, M. Ehara, K. Toyota, R. Fukuda, J. Hasegawa, M. Ishida, T. Nakajima, Y. Honda, O. Kitao, H. Nakai, M. Klene, X. Li, J.E. Knox, H.P. Hratchian, J.B. Cross, V. Bakken, C. Adamo, J. Jaramillo, R. Gomperts, R.E. Stratmann, O. Yazyev, A.J. Austin, R. Cammi, C. Pomelli, J.W. Ochterski, P.Y. Ayala, K. Morokuma, G.A.S. Voth, P., J.J. Dannenberg, V.G. Zakrzewski, S. Dapprich, A.D. Daniels, M.C. Strain, O. Farkas, D.K. Malick, A.D. Rabuck, K. Raghavachari, J.B. Foresman, J.V. Ortiz, Q. Cui, A.G. Baboul, S. Clifford, J. Cioslowski, B.B. Stefanov, G. Liu, A. Liashenko, P. Piskorz, I. Komaromi, R.L. Martin, D.J. Fox, T. Keith, M.A. Al-Laham, C.Y. Peng, A. Nanayakkara, M. Challacombe, P.M.W. Gill, B. Johnson, W. Chen, M.W. Wong, C. Gonzalez, J.A. Pople, Inc., Pittsburgh PA.

[45] A.D. Becke, J. Chem. Phys., 98 (1993) 5648-5652.

[46] B. Miehlich, A. Savin, H. Stoll, H. Preuss, Chem. Phys. Lett., 157 (1989) 200-206.

[47] C. Lee, W. Yang, R.G. Parr, Phys. Rev. B, 37 (1988) 785-789.

[48] W.R. Wadt, P.J. Hay, J. Chem. Phys., 82 (1985) 284-298.

[49] P.J. Hay, W.R. Wadt, J. Chem. Phys., 82 (1985) 270-283.

[50] L.E. Roy, P.J. Hay, R.L. Martin, J. Chem. Theory Comput. , 4 (2008) 1029-1031.

[51] C.E. Welby, L. Gilmartin, R.R. Marriott, A. Zahid, C.R. Rice, E.A. Gibson, P.I. Elliott, Dalton Trans., 42 (2013) 13527-13536. 
[52] J. Forniés, S. Fuertes, A. Martín, V. Sicilia, B. Gil, E. Lalinde, Dalton Trans., (2009) 22242234.

[53] S. Jamali, M.M. Ashtiani, Z. Jamshidi, E. Lalinde, M.T. Moreno, H. Samouei, E. EscuderoAdán, J. Benet-Buchholz, Inorg. Chem., 52 (2013) 10729-10731.

[54] J. Forniés, N. Giménez, S. Ibáñez, E. Lalinde, A. Martín, M.T. Moreno, Inorg. Chem., 54 (2015) 4351-4363. 
Graphical abstract for the contents pages

Newly Designed Luminescent Di- and Tetranuclear Double Rollover Cycloplatinated(II) Complexes

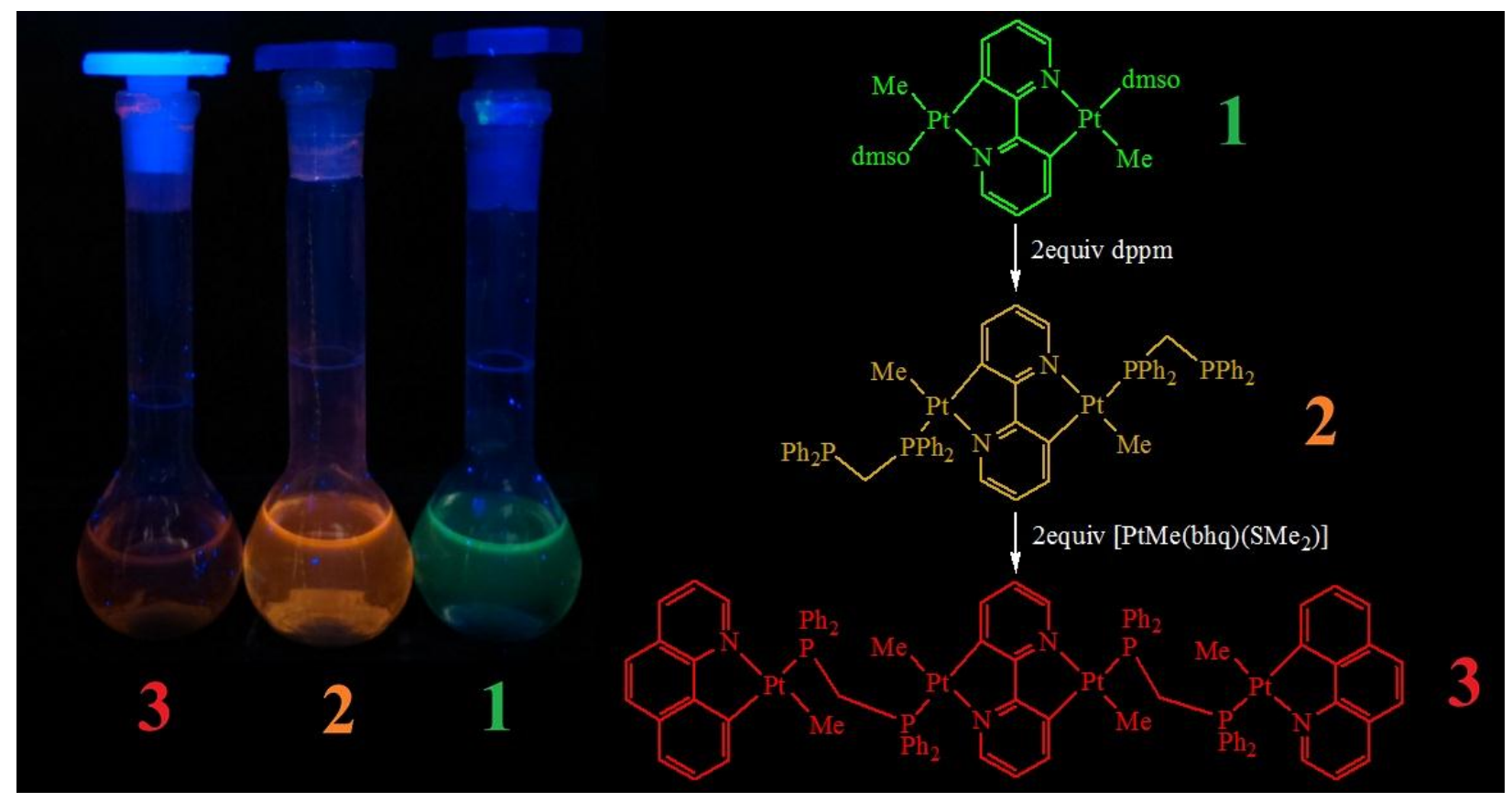

